\title{
8-Amino-6-Methoxyquinoline-Tetrazole Hybrids: Impact of Linkers on Antiplasmodial Activity
}

\author{
Patrick Hochegger ${ }^{1, *(\mathbb{D} \text {, Johanna Dolensky }}{ }^{1}$, Werner Seebacher ${ }^{1}$, Robert Saf ${ }^{2}$, Marcel Kaiser ${ }^{3}$, Pascal Mäser ${ }^{3}$ (D) \\ and Robert Weis ${ }^{1}$ \\ 1 Institute of Pharmaceutical Sciences, Pharmaceutical Chemistry, University of Graz, Schubertstraße 1, \\ A-8010 Graz, Austria; johanna.faist@uni-graz.at (J.D.); we.seebacher@uni-graz.at (W.S.); \\ robert.weis@uni-graz.at (R.W.) \\ 2 Institute for Chemistry and Technology of Materials (ICTM), Graz University of Technology, Stremayrgasse 9, \\ A-8010 Graz, Austria; robert.saf@tugraz.at \\ 3 Swiss Tropical and Public Health Institute, Socinstraße 57, CH-4002 Basel, Switzerland; \\ marcel.kaiser@swisstph.ch (M.K.); pascal.maeser@swisstph.ch (P.M.) \\ * Correspondence: patrick.hochegger@uni-graz.at; Tel.: +43-316-380-5379; Fax: +43-316-380-9846
}

Citation: Hochegger, P.; Dolensky, J.; Seebacher, W.; Saf, R.; Kaiser, M.; Mäser, P.; Weis, R. 8-Amino-6Methoxyquinoline-Tetrazole Hybrids: Impact of Linkers on Antiplasmodial Activity. Molecules 2021, 26, 5530. https://doi.org/ $10.3390 /$ molecules 26185530

Academic Editor: Sandra Gemma

Received: 18 August 2021

Accepted: 10 September 2021

Published: 12 September 2021

Publisher's Note: MDPI stays neutral with regard to jurisdictional claims in published maps and institutional affiliations.

Copyright: (c) 2021 by the authors. Licensee MDPI, Basel, Switzerland. This article is an open access article distributed under the terms and conditions of the Creative Commons Attribution (CC BY) license (https:/ / creativecommons.org/licenses/by/ $4.0 /)$.

\begin{abstract}
A new series of compounds was prepared from 6-methoxyquinolin-8-amine or its $N$ (2-aminoethyl) analogue via Ugi-azide reaction. Their linkers between the quinoline and the tertbutyltetrazole moieties differ in chain length, basicity and substitution. Compounds were tested for their antiplasmodial activity against Plasmodium falciparum NF54 as well as their cytotoxicity against L-6-cells. The activity and the cytotoxicity were strongly influenced by the linker and its substitution. The most active compounds showed good activity and promising selectivity.
\end{abstract}

Keywords: antimalarial; tetrazole derivatives; Plasmodium falciparum; 8-aminoquinolines

\section{Introduction}

Malaria, a vector-borne parasitic disease, is still one of the most dangerous infectious diseases worldwide. With more than 200 million cases in 2019 and 400.000 deaths malaria is a huge burden for mostly sub-Saharan African, South American, Southeast Asian countries [1]. Mostly children under the age of five are prone to a critical and fatal course of disease. Malaria is caused by one of five human pathogens of the genus Plasmodium with Plasmodium falciparum and Plasmodium vivax being responsible for most of the infections. P. falciparum is responsible for a majority of fatal outcomes and is therefore considered the deadliest parasite of these five pathogens [2]. Especially P. falciparum's rapid development of resistances against established drugs is of concern. Even against artemisinin derivatives, which are usually combined with other drugs in the first-line treatment of malaria, first resistances are emerging $[3,4]$. Because of the threat of potentially untreatable malaria infections new active compounds are urgently needed.

The discovery of chloroquine in the 1960s was an essential early turning point to improve malaria treatment. Unfortunately, first resistances were discovered fairly soon. However, chloroquine with its quinoline moiety is still an attractive pharmcophore, possessing limited toxicity, simple cost-effective synthesis and high clinical efficacy [5-7]. A promising strategy for developing new antimalarials and circumventing resistances is quinoline hybridization $[8,9]$

Pandey et al. published a series of compounds where a 4-aminochinoline moiety was linked with a tetrazole ring. In this case an aminophenyl motive functioned as a linker. These compounds possessed antimalarial activities in the submicromolar range. Especially the tetrazole ring was supposed to be important for complexing heme [10]. Recently we published a series of 7-chloroquinoline derivatives that were linked with a tetrazole ring as well as different lipophilic aliphatic and aromatic side chains. A piperidine ring was 
used as a linker instead of the aminophenyl moiety. These compounds showed distinct antimalarial activities [11].

The focus of the current work was the synthesis of novel active compounds by using a hybridization approach. The 8-amino-6-methoxyquinoline pharmacophore is part of antimalarials like primaquine and tafenoquine and was therefore used as a central element of the new derivatives. (Figure 1) It was linked to a tetrazole ring via different linkers. Furthermore, lipophilic side chains were varied. All new compounds were characterized and tested in vitro for their activities against $P$. falciparum. The results were compared to those of formerly prepared analogues and of drugs in use.<smiles>COc1cc(NC(C)CCCN)c2ncccc2c1</smiles>

primaquine<smiles>COc1cc(C)c2c(Oc3cccc(C(F)(F)F)c3)c(OC)cc(NC(C)CCCN)c2n1</smiles>

tafenoquine

Figure 1. Structures of primaquine and tafenoquine.

\section{Results and Discussion}

\subsection{Chemistry}

As precursor for all final compounds served 6-methoxyquinolin-8-amine 2, which was synthesized in a two-step reaction from 4-methoxy-2-nitroaniline and glycerol in a so called Skraup reaction [12]. This reaction resulted in 6-methoxy-8-nitroquinoline $\mathbf{1}$, which was further reduced by $\mathrm{SnCl}_{2}$ to 6-methoxyquinolin-8-amine 2 [13].

Compounds 13-22 were obtained by an Ugi-azide reaction of amine 2 with tert-butyl isocyanide, trimethylsilyl azide and various aldehydes to investigate the influence of different side chains adjacent to the newly formed tetrazole group [14].

In case of compounds 7-12 an additional ethyl linker was integrated into the molecule to examine how a greater distance between the 8-amino group of the quinoline moiety and the tetrazole ring impacts the activity. A straightforward nucleophilic substitution reaction of compound $\mathbf{2}$ with 2-chloroethyl-1-amine hydrochloride to amine $\mathbf{6}$ did not give any product. Therefore, we looked for a different approach and the linker was synthesized via multiple steps. At first compound 2 reacted with chloroacetyl chloride to an amide $3[15,16]$. The terminal chloro group of the newly formed compound was subsequently substituted by an azide group using sodium azide in DMF as solvent [16]. This azide group of 4 was converted to an amine in a Staudinger reaction by using triphenylphosphine [16]. In a final reaction with $\mathrm{LiAlH}_{4}$ the amide group of 5 was reduced yielding amine 6 [17]. Different synthesis methods for compounds 3,5 and $\mathbf{6}$ are known, but without any NMR data given for these substances [18-21].

Afterwards compound 6 was converted to compounds 7-12 via Ugi-azide reactions. For this reaction the aldehyde component was varied to obtain compounds with different aliphatic and aromatic side chains close to the tetrazole moiety (Scheme 1) [14]. 
Molecules 2021, 26, 5530

3 of 13<smiles>COc1ccc(N)c([N+](=O)[O-])c1</smiles><smiles>OCC(O)CO</smiles>

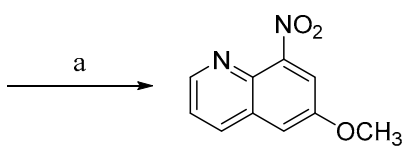

1
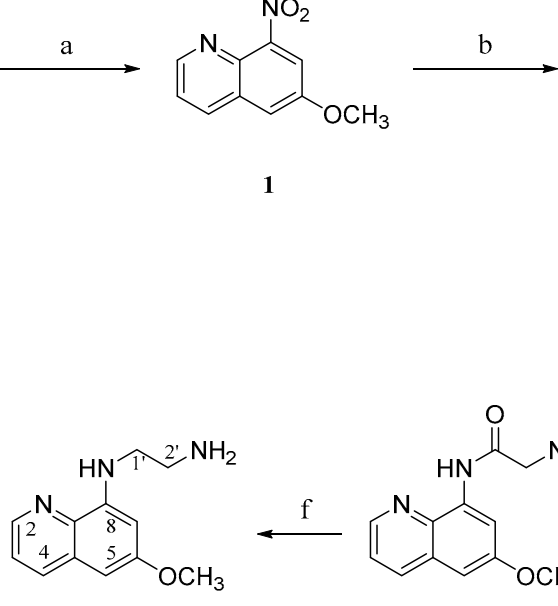

6

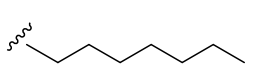

22

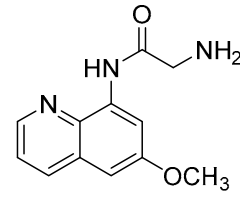

5

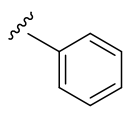

8,14

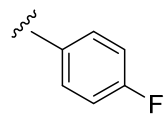

9,15

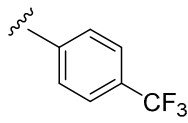

12,18

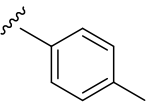

19

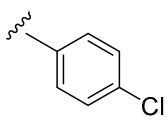

10,16

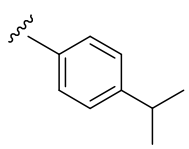

20<smiles>COc1cc(N)c2ncccc2c1</smiles>

2

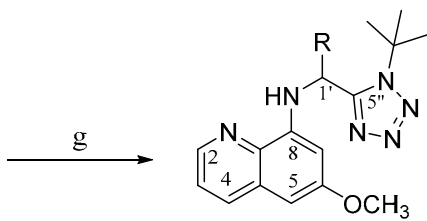

13-22
$\mathrm{R}=\mathrm{s}^{\mathrm{s}}$

7,13

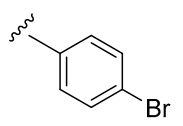

11, 17

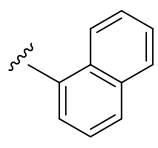

21

Scheme 1. Preparation of compounds 1-22, Reagents and conditions: (a) $\mathrm{FeSO}_{4} \times 7 \mathrm{H}_{2} \mathrm{O}$, methanesulfonic acid, $130{ }^{\circ} \mathrm{C}, 6 \mathrm{~h}$; (b) $\mathrm{SnCl}_{2} \times 2 \mathrm{H}_{2} \mathrm{O}, \mathrm{EtOH}, \mathrm{rt}, 48 \mathrm{~h}$; (c) chloroacetyl chloride, triethylamine, $\mathrm{CH}_{2} \mathrm{Cl}_{2}, \mathrm{rt}, 20 \mathrm{~h}$; (d) NaN, $\mathrm{DMF}$, rt, 48 h; (e) triphenylphosphine, THF, H2O, reflux, 20 h; (f) $\mathrm{LiAlH}_{4}$, diethyl ether, rt, $20 \mathrm{~h}$; (g) aldehyde, trimethylsilyl azide, tert-butyl isocyanide, $\mathrm{MeOH}, \mathrm{rt}, 20-120 \mathrm{~h}$.

The structures of all newly synthesized compounds were clarified by one- and twodimensional NMR spectroscopy. Products of the Ugi-azide reaction showed characteristic signals in the NMR spectra of compounds 7-22. Their tert-butyl group gave an intense proton resonance at low frequencies as well as carbon resonances at about 30 and $61.5 \mathrm{ppm}$. A longrange coupling was observed from their new methine proton to the tetrazole carbon which gave resonances at 155-157 ppm depending on substitution of the methine carbon atom. ${ }^{1} \mathrm{H}$ - and ${ }^{13} \mathrm{C}-\mathrm{NMR}$-spectra are given in the Supplementary Materials.

2.2. Antiplasmodial Activity and Cytotoxicity

All compounds were tested for their antiplasmodial activity against the chloroquinesensitive strain NF54 of $P$. falciparum. Further on their cytotoxicity was determined using skeletal myoblasts (L-6 cells). As standards served chloroquine and podophyllotoxin (Table 1).

The prepared compounds showed heterogeneous activities against $P$. falciparum NF54. Compounds 7-12 with a basic (methylamino)ethyl linker were usually way less active $\left(\right.$ PfNF54 IC $\left._{50}=15.98-2.51 \mu \mathrm{M}\right)$ than compounds 15-22 with a methyl linker $\left(\right.$ PfNF54 IC $_{50}=$ $2.68-0.324 \mu \mathrm{M})$ with the exception of compounds 13 and $14\left(P f \mathrm{NF}_{4} \mathrm{IC}_{50}=23.60-5.12 \mu \mathrm{M}\right)$. 
Table 1. Activities of compounds 7-22 against P. falciparum NF54, and L-6 cells, expressed as $\mathrm{IC}_{50}(\mu \mathrm{M})^{\mathrm{a}}$.

\begin{tabular}{|c|c|c|c|}
\hline Compound & P.f. NF54 ${ }^{\mathrm{b}} \mathrm{IC}_{50}(\mu \mathrm{M})$ & S.I. $=\mathrm{IC}_{50}($ Cyt. $) / \mathrm{IC}_{50}($ P.f. NF54) & Cytotoxicity L-6 Cells $\mathrm{IC}_{50}(\mu \mathrm{M})$ \\
\hline 7 & 15.98 & 15.98 & 144.0 \\
\hline 8 & 6.09 & 9.52 & 57.97 \\
\hline 9 & 7.05 & 7.86 & 55.43 \\
\hline 10 & 5.34 & 17.29 & 92.31 \\
\hline 11 & 2.51 & 13.57 & 34.07 \\
\hline 12 & 2.92 & 7.64 & 22.30 \\
\hline 13 & 23.60 & 3.86 & 91.10 \\
\hline 14 & 5.12 & 9.56 & 48.96 \\
\hline 15 & 2.68 & 46.27 & 124.0 \\
\hline 16 & 0.743 & 318.3 & 236.5 \\
\hline 17 & 0.464 & 208.8 & 96.86 \\
\hline 18 & 0.644 & 273.3 & 176.0 \\
\hline 19 & 1.04 & 238.9 & 248.5 \\
\hline 20 & 2.00 & 59.70 & 119.4 \\
\hline 21 & 1.26 & 137.6 & 173.4 \\
\hline 22 & 0.324 & 168.9 & 54.73 \\
\hline $\mathrm{CQ}$ & 0.0039 & 23,313 & 90.92 \\
\hline POD & & & 0.012 \\
\hline
\end{tabular}

$\mathrm{CQ}=$ chloroquine; $\mathrm{POD}=$ podophyllotoxin. ${ }^{\mathrm{a}}$ values represent the average of four determinations (two determinations of two independent experiments); ${ }^{b}$ sensitive to chloroquine.

In the case of compounds 7-12 the least active compound was $\mathbf{7}\left(\operatorname{PfNF54} \mathrm{IC}_{50}=\right.$ $15.98 \mu \mathrm{M})$ with an ethyl side chain. A more lipophilic phenyl ring as side chain improved antiplasmodial activity in general, which is apparent in compounds 8-12 (Pf NF54 $\mathrm{IC}_{50}=$ 7.05-2.51 $\mu \mathrm{M})$. In this series the most active compounds were $\mathbf{1 1}$ and $\mathbf{1 2}\left(\mathrm{PfNF} 54 \mathrm{IC}_{50}=\right.$ 2.92-2.51 $\mu \mathrm{M}$ ) with a 4-bromophenyl and a 2-(trifluoromethyl)phenyl side chain, respectively. Replacement of the bromine atom by a hydrogen, a fluorine or a chlorine atom led to less active compounds 8-10 (PfNF54 $\left.\mathrm{IC}_{50}=7.05-5.34 \mu \mathrm{M}\right)$.

Compounds 13-22 with the methyl linker were generally more active. The least active compound $13\left(P f N F 54 \mathrm{IC}_{50}=23.60 \mu \mathrm{M}\right)$ was again the one with the ethyl side chain. Its more lipophilic phenyl analogue $14\left(\right.$ PfNF54 $\left.\mathrm{IC}_{50}=5.12 \mu \mathrm{M}\right)$ showed improved, but still weak activity. Substitution in ring position 4 of the phenyl ring with a fluorine atom, a methyl or an isopropyl group as well as its replacement with a 1-naphthyl moiety further increased the antiplasmodial activity (15 and 19-21 Pf NF54 $\left.\mathrm{IC}_{50}=2.68-1.04 \mu \mathrm{M}\right)$. Compounds with bulkier electron withdrawing substituents like 16-18 (PfNF54 $\mathrm{IC}_{50}=$

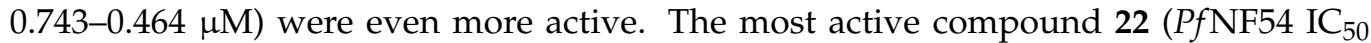
$=0.324 \mu \mathrm{M})$ possesses a heptyl side chain. This indicates a positive impact of highly lipophilic and voluminous side chains. However, an additional stereochemical effect could be relevant, because the 1-naphthyl analogue 21 (PfNF54 $\left.\mathrm{IC}_{50}=1.26 \mu \mathrm{M}\right)$ was significantly less active. Compounds 15 and $20\left(P f N F 54 \mathrm{IC}_{50}=2.68-2.00 \mu \mathrm{M}\right)$ showed low cytotoxicity $\left(\mathrm{L}-6\right.$ cells $\left.\mathrm{IC}_{50}=119.4-124.0 \mu \mathrm{M}\right)$ and good selectivity (S.I. $\left.=46.27-59.7\right)$. The most active compounds 16-19 and 21-22 (PfNF54 $\left.\mathrm{IC}_{50}=1.26-0.324 \mu \mathrm{M}\right)$ also showed low cytotoxicity $\left(\mathrm{L}-6\right.$ cells $\left.\mathrm{IC}_{50}=54.73-248.5 \mu \mathrm{M}\right)$ resulting in promising selectivity (S.I. = 137.6-318.3). 


\section{Materials and Methods}

\subsection{Instrumentation and Chemicals}

Materials: Solvents and reagents were used without further purification. Dry solvents were either purchased in sealed bottles or were dried over molecular sieves or dried with sodium. Column chromatography (CC): silica gel 60 (Merck 70-230 mesh, pore diameter $60 \AA$ ), aluminium oxide (pH: 9.5, Fluka). Thin-layer chromatography (TLC): TLC plates silica gel 60 F254 (Merck), aluminium oxide 60 F254 (neutral, Merck). Melting points were obtained on an Electrothermal IA 9200 melting point apparatus. IR spectra: Bruker Alpha Platinum ATR FTIR spectrometer (KBr discs); frequencies are reported in $\mathrm{cm}^{-1}$. The structures of all newly synthesized compounds were determined by one- and twodimensional NMR spectroscopy. NMR spectra: Varian UnityInova 400 (298 K) $5 \mathrm{~mm}$ tubes, TMS as internal standard. Shifts in ${ }^{1} \mathrm{H}$ NMR $(400 \mathrm{MHz})$ and ${ }^{13} \mathrm{C}$ NMR $(100 \mathrm{MHz})$ spectra are reported in ppm; ${ }^{1} \mathrm{H}$ - and ${ }^{13} \mathrm{C}$-resonances were assigned using ${ }^{1} \mathrm{H},{ }_{1}^{1} \mathrm{H}$ - and ${ }^{1} \mathrm{H},{ }^{13} \mathrm{C}$-correlation spectra and are numbered as given in Scheme 1 . Signal multiplicities are abbreviated as follows: br, broad; $d$, doublet; dd, doublet of doublets; ddd, doublet of doublet of doublets; $\mathrm{dt}$, doublet of triplets; $\mathrm{m}$, multiplet; s, singlet; $\mathrm{t}$, triplet; $\mathrm{td}$, triplet of doublets; q, quartet. HRMS: Micromass Tofspec 3E spectrometer (MALDI) and GCTPremier, Waters (EI, 70eV). ${ }^{1} \mathrm{H}-\mathrm{NMR}$ and ${ }^{13} \mathrm{C}-\mathrm{NMR}$ spectra of new compounds are available in Supplementary Materials (Figures S1-S20).

\subsection{Syntheses}

Compounds 6-methoxy-8-nitroquinoline 1, and 6-methoxyquinoline-8-amine 2 were synthesized according to an already published protocol and their NMR data were in accordance with literature data [12,13].

2-Chloro-N-(6-methoxyquinolin-8-yl)acetamide (3): 6-Methoxyquinolin-8-amine 2 (0.523 g $(3.00 \mathrm{mmol}))$ was dissolved in in dry $\mathrm{CH}_{2} \mathrm{Cl}_{2}(15 \mathrm{~mL})$ and cooled to $0{ }^{\circ} \mathrm{C}$ with an ice bath. Triethylamine $(2.079 \mathrm{~mL}(15.00 \mathrm{mmol}))$ was added and the mixture was stirred for $10 \mathrm{~min}$. Chloroacetyl chloride $(0.477 \mathrm{~mL}(6.00 \mathrm{mmol}))$ in dry $\mathrm{CH}_{2} \mathrm{Cl}_{2}(15 \mathrm{~mL})$ was added dropwise via a dropping funnel. The ice bath was removed and the reaction mixture stirred at $25^{\circ} \mathrm{C}$ for $20 \mathrm{~h}$. Then, the reaction was quenched with $2 \mathrm{~N} \mathrm{NaOH}$ at $0{ }^{\circ} \mathrm{C}$ and the mixture was basified to a $\mathrm{pH}$ of 10-11. The aqueous and organic phases were separated and the aqueous phase was extracted with $\mathrm{CH}_{2} \mathrm{Cl}_{2}$. The combined organic phases were washed with $0.1 \%$ aqueous $\mathrm{NaHCO}_{3}$ and dried over anhydrous sodium sulfate and filtered. The solvent was removed in vacuo and the obtained raw product purified by column chromatography (silica gel, diethyl ether) to yield compound 3 as off-white amorphous solid $(0.700 \mathrm{~g}(93 \%)$ ). ${ }^{1} \mathrm{H} \mathrm{NMR}\left(\mathrm{CDCl}_{3}, 400 \mathrm{MHz}\right) \delta=3.72\left(\mathrm{~s}, 3 \mathrm{H}, \mathrm{OCH}_{3}\right), 4.15\left(\mathrm{~s}, 2 \mathrm{H}, \mathrm{CH}_{2} \mathrm{Cl}\right), 6.58(\mathrm{~d}, J=2.6 \mathrm{~Hz}$, $1 \mathrm{H}, 5-\mathrm{H}), 7.19(\mathrm{dd}, J=8.2,4.2 \mathrm{~Hz}, 1 \mathrm{H}, 3-\mathrm{H}), 7.80(\mathrm{dd}, J=8.2,1.6 \mathrm{~Hz}, 1 \mathrm{H}, 4-\mathrm{H}), 8.25(\mathrm{~d}$, $J=2.6 \mathrm{~Hz}, 1 \mathrm{H}, 7-\mathrm{H}), 8.46(\mathrm{dd}, J=4.1,1.6 \mathrm{~Hz}, 1 \mathrm{H}, 2-\mathrm{H}), 10.60(\mathrm{~s}, 1 \mathrm{H}, \mathrm{NH}) ;{ }^{13} \mathrm{C} \mathrm{NMR}\left(\mathrm{CDCl}_{3}\right.$, $100 \mathrm{MHz}) \delta=43.10\left(\mathrm{CH}_{2} \mathrm{Cl}\right), 55.26\left(\mathrm{OCH}_{3}\right), 100.05(\mathrm{C}-5), 108.91(\mathrm{C}-7), 121.90(\mathrm{C}-3), 128.51$ (C-4a), 133.97 (C-8), 134.55 (C-4), 134.78 (C-8a), 145.69 (C-2), 157.75 (C-6), 164.03 (CO).

2-Azido-N-(6-methoxyquinolin-8-yl)acetamide (4): Compound 3 (0.702 g (2.80 mmol)) was dissolved in dry DMF $(30 \mathrm{~mL})$ and cooled to $0{ }^{\circ} \mathrm{C}$ with an ice bath. Sodium azide $(0.364 \mathrm{~g}$ $(5.60 \mathrm{mmol})$ ) was added in small portions and after that the ice bath was removed and the reaction mixture stirred at $25^{\circ} \mathrm{C}$ for $48 \mathrm{~h}$. Then, the reaction was quenched with $0.1 \%$ aqueous $\mathrm{NaHCO}_{3}(50 \mathrm{~mL})$. The aqueous phase was extracted with ethyl acetate. The combined organic phases were washed with $0.1 \%$ aqueous $\mathrm{NaHCO}_{3}$ and dried over anhydrous sodium sulfate and filtered. The solvent was removed in vacuo and the obtained raw product purified by column chromatography (silica gel, ethyl acetate/ethanol 6:1) to yield compound 4 as off-white amorphous solid $(0.634 \mathrm{~g}(88 \%)) .{ }^{1} \mathrm{H} \mathrm{NMR}\left(\mathrm{CDCl}_{3}\right.$, $400 \mathrm{MHz}) \delta=3.85\left(\mathrm{~s}, 3 \mathrm{H}, \mathrm{OCH}_{3}\right), 4.21\left(\mathrm{~s}, 2 \mathrm{H}, \mathrm{CH}_{2} \mathrm{~N}_{3}\right), 6.71(\mathrm{~d}, J=2.6 \mathrm{~Hz}, 1 \mathrm{H}, 5-\mathrm{H}), 7.33(\mathrm{dd}$, $J=8.2,4.3 \mathrm{~Hz}, 1 \mathrm{H}, 3-\mathrm{H}), 7.93(\mathrm{dd}, J=8.2,1.6 \mathrm{~Hz}, 1 \mathrm{H}, 4-\mathrm{H}), 8.40(\mathrm{~d}, J=2.6 \mathrm{~Hz}, 1 \mathrm{H}, 7-\mathrm{H}), 8.60$ $(\mathrm{dd}, J=4.3,1.6 \mathrm{~Hz}, 1 \mathrm{H}, 2-\mathrm{H}), 10.38(\mathrm{br} \mathrm{s}, 1 \mathrm{H}, \mathrm{NH}) ;{ }^{13} \mathrm{C} \mathrm{NMR}\left(\mathrm{CDCl}_{3}, 100 \mathrm{MHz}\right) \delta=52.93$ 
$\left(\mathrm{CH}_{2} \mathrm{~N}_{3}\right), 55.10\left(\mathrm{OCH}_{3}\right), 99.80$ (C-5), 108.88 (C-7), 121.74 (C-3), 128.41 (C-4a), 133.84 (C-8), 134.45 (C-4), 134.53 (C-8a), 145.49 (C-2), 157.65 (C-6), 164.70 (CO).

2-Amino-N-(6-methoxyquinolin-8-yl)acetamide (5): Compound 4 (0.630 g (2.45 mmol)) was dissolved in THF/ $\mathrm{H}_{2} \mathrm{O}$ 6:1 $(40 \mathrm{~mL})$ at room temperature. Triphenylphosphine (1.26 g $(4.90 \mathrm{mmol}))$ was added in small portions. Followed by that the brown reaction mixture was refluxed for $20 \mathrm{~h}$. The mixture was cooled to room temperature and the solvent removed in vacuo. The residue was adsorbed on a column with silica gel and excess triphenylphosphine and triphenylphospine oxide were removed by elution with diethyl ether. Elution of the product with $\mathrm{CH}_{2} \mathrm{Cl}_{2} / \mathrm{MeOH}$ 1:1 afforded a raw product which was further purified by column chromatography (silica gel, ethyl acetate/ethanol 6:1) to yield compound 5 as orange amorphous solid $(0.504 \mathrm{~g}(89 \%)) .{ }^{1} \mathrm{H} \mathrm{NMR}\left(\mathrm{CDCl}_{3}, 400 \mathrm{MHz}\right)$ $\delta=1.75\left(\mathrm{br} \mathrm{s}, 2 \mathrm{H}, \mathrm{NH}_{2}\right), 3.65\left(\mathrm{~s}, 2 \mathrm{H}, \mathrm{CH}_{2}\right), 3.93\left(\mathrm{~s}, 3 \mathrm{H}, \mathrm{OCH}_{3}\right), 6.81(\mathrm{~d}, J=2.8 \mathrm{~Hz}, 1 \mathrm{H}, 5-\mathrm{H})$, $7.39(\mathrm{dd}, J=8.3,4.2 \mathrm{~Hz}, 1 \mathrm{H}, 3-\mathrm{H}), 8.03(\mathrm{~d}, J=8.3,1.5 \mathrm{~Hz}, 1 \mathrm{H}, 4-\mathrm{H}), 8.57(\mathrm{~d}, J=2.8 \mathrm{~Hz}, 1 \mathrm{H}$, $7-\mathrm{H}), 8.70(\mathrm{dd}, J=4.2,1.5 \mathrm{~Hz}, 1 \mathrm{H}, 2-\mathrm{H}), 11.25(\mathrm{br} \mathrm{s}, 1 \mathrm{H}, \mathrm{NH}) ;{ }^{13} \mathrm{C} \mathrm{NMR}\left(\mathrm{CDCl}_{3}, 100 \mathrm{MHz}\right)$ $\delta=46.09\left(\mathrm{CH}_{2}\right), 55.45\left(\mathrm{OCH}_{3}\right), 99.91(\mathrm{C}-5), 108.92(\mathrm{C}-7), 121.95(\mathrm{C}-3), 129.03(\mathrm{C}-4 \mathrm{a}), 134.92$ (C-4), 135.11 (C-8), 135.53 (C-8a), 145.94 (C-2), 158.37 (C-6), 171.55 (CO).

$N^{1}$-(6-Methoxyquinolin-8-yl)ethan-1,2-diamine (6): Compound 5 (0.509 g (2.20 mmol)) was dissolved in dry diethyl ether $(30 \mathrm{~mL})$ and cooled to $0{ }^{\circ} \mathrm{C}$ with an ice bath. Pulverized $\mathrm{LiAlH}_{4}(0.167 \mathrm{~g}(4.40 \mathrm{mmol}))$ was added slowly in small portions and the reaction mixture was stirred for $30 \mathrm{~min}$ at $0{ }^{\circ} \mathrm{C}$. Then the mixture was refluxed for $20 \mathrm{~h}$. The suspension was cooled to $0{ }^{\circ} \mathrm{C}$ and quenched with $2 \mathrm{~N} \mathrm{NaOH}$ and was basified to a $\mathrm{pH}$ of $10-11$. The aqueous and organic phases were separated and the aqueous phase was extracted with diethyl ether. The combined organic phases were dried over anhydrous sodium sulfate and filtered. The solvent was removed in vacuo and the obtained raw product purified by column chromatography (silica gel, $\mathrm{CH}_{2} \mathrm{Cl}_{2} / \mathrm{MeOH}$ 5:1) to yield compound 6 as off-white amorphous solid $(0.277 \mathrm{~g}(58 \%))$. ${ }^{1} \mathrm{H}$ NMR $\left(\mathrm{CDCl}_{3}, 400 \mathrm{MHz}\right) \delta=1.40\left(\mathrm{br} \mathrm{s}, 2 \mathrm{H}, \mathrm{NH}_{2}\right), 3.07$ $\left(\mathrm{t}, J=6.0 \mathrm{~Hz}, 2 \mathrm{H}, 2^{\prime}-\mathrm{H}\right), 3.37\left(\mathrm{q}, J=6.0 \mathrm{~Hz}, 2 \mathrm{H}, 1^{\prime}-\mathrm{H}\right), 3.89\left(\mathrm{~s}, 3 \mathrm{H}, \mathrm{OCH}_{3}\right), 6.31-6.38(\mathrm{~m}, 1 \mathrm{H}$, $\mathrm{NH}), 6.34(\mathrm{~d}, J=2.5 \mathrm{~Hz}, 1 \mathrm{H}, 7-\mathrm{H}), 6.37(\mathrm{~d}, J=2.5 \mathrm{~Hz}, 1 \mathrm{H}, 5-\mathrm{H}), 7.31(\mathrm{dd}, J=8.3,4.2 \mathrm{~Hz}, 1 \mathrm{H}$, $3-\mathrm{H}), 7.93(\mathrm{dd}, J=8.3,1.2 \mathrm{~Hz}, 1 \mathrm{H}, 4-\mathrm{H}), 8.55(\mathrm{dd}, J=4.2,1.2 \mathrm{~Hz}, 1 \mathrm{H}, 2-\mathrm{H}) ;{ }^{13} \mathrm{C} \mathrm{NMR}\left(\mathrm{CDCl}_{3}\right.$, $100 \mathrm{MHz}) \delta=40.93\left(\mathrm{C}-2^{\prime}\right), 46.18\left(\mathrm{C}-1^{\prime}\right), 55.08\left(\mathrm{OCH}_{3}\right), 92.10(\mathrm{C}-5), 96.76(\mathrm{C}-7), 121.73(\mathrm{C}-3)$, 129.64 (C-4a), 134.62 (C-4), 135.29 (C-8a), 144.35 (C-2), 145.78 (C-8), 159.25 (C-6).

The general procedure for the Ugi-azide reaction (7-22) is as follows: 6-Methoxyquinoline-8amine $2(0.75 \mathrm{mmol})$ or compound $6(0.75 \mathrm{mmol})$ were dissolved in dry methanol $(5 \mathrm{~mL})$. The corresponding aldehyde $(0.75 \mathrm{mmol})$ was added and the mixture stirred at room temperature for $1 \mathrm{~h}$ under an argon atmosphere. Trimethylsilyl azide $(0.75 \mathrm{mmol})$ and tert-butyl isocyanide $(0.75 \mathrm{mmol})$ were added dropwise and the reaction mixture was stirred for 20-120 h. After that, the solvent was evaporated in vacuo and the residue was dissolved in $\mathrm{CH}_{2} \mathrm{Cl}_{2}$. The solution was washed several times with $30 \%$ aqueous sodium disulfite followed by $0.1 \%$ aqueous $\mathrm{NaHCO}_{3}$. The organic phase was dried over anhydrous sodium sulfate and filtered. The solvent was removed in vacuo, yielding the raw products 7-22, which were further purified by column chromatography.

$N^{1}$-(6-Methoxyquinolin-8-yl)- $N^{2}$-(1-(tert-butyl-1H-tetrazol-5-yl)propyl)ethan-1,2-diamine (7): The reaction of compound 6 (163 mg $(0.75 \mathrm{mmol}))$, propanal $(44 \mathrm{mg}, 54 \mu \mathrm{L}(0.75 \mathrm{mmol}))$, trimethylsilyl azide $(86 \mathrm{mg}, 100 \mu \mathrm{L}(0.75 \mathrm{mmol}))$ and tert-butyl isocyanide $(62 \mathrm{mg}, 85 \mu \mathrm{L}$ $(2.00 \mathrm{mmol}))$ in dry methanol $(5 \mathrm{~mL})$ gave the raw tetrazole which was purified by column chromatography (silica gel, diethyl ether) to yield compound 7 as yellow oil (63 $\mathrm{mg}(22 \%)$ ). $\mathrm{IR}=2959,1618,1579,1519,1459,1425,1390,1211,1152,1115,918,828,794 ;{ }^{1} \mathrm{H}$ NMR $\left(\mathrm{CDCl}_{3}, 400 \mathrm{MHz}\right) \delta=1.04\left(\mathrm{t}, J=7.3 \mathrm{~Hz}, 3 \mathrm{H}, 3^{\prime \prime}-\mathrm{H}\right), 1.72\left(\mathrm{~s}, 9 \mathrm{H},\left(\mathrm{CH}_{3}\right)_{3}\right), 1.87-1.97(\mathrm{~m}$, $\left.3 \mathrm{H}, 2^{\prime \prime}-\mathrm{H}, \mathrm{NH}\right), 2.83\left(\mathrm{dt}, J=11.9,6.0 \mathrm{~Hz}, 1 \mathrm{H}, 2^{\prime}-\mathrm{H}\right), 2.92\left(\mathrm{dt}, J=11.9,5.8 \mathrm{~Hz}, 1 \mathrm{H}, 2^{\prime}-\mathrm{H}\right)$, 3.30-3.37 (m, 2H, 1'-H), $3.88\left(\mathrm{~s}, 3 \mathrm{H}, \mathrm{OCH}_{3}\right), 4.17\left(\mathrm{t}, \mathrm{J}=6.6 \mathrm{~Hz}, 1 \mathrm{H}, 1^{\prime \prime}-\mathrm{H}\right), 6.28(\mathrm{~d}, J=2.5 \mathrm{~Hz}$, $1 \mathrm{H}, 7-\mathrm{H}), 6.36(\mathrm{~d}, J=2.5 \mathrm{~Hz}, 1 \mathrm{H}, 5-\mathrm{H}), 6.44-6.49(\mathrm{~m}, 1 \mathrm{H}, \mathrm{NH}), 7.30(\mathrm{dd}, J=8.3,4.2 \mathrm{~Hz}$, $1 \mathrm{H}, 3-\mathrm{H}), 7.92(\mathrm{dd}, J=8.3,1.4 \mathrm{~Hz}, 1 \mathrm{H}, 4-\mathrm{H}), 8.53(\mathrm{dd}, J=4.2,1.4 \mathrm{~Hz}, 1 \mathrm{H}, 2-\mathrm{H}) ;{ }^{13} \mathrm{C} \mathrm{NMR}$ $\left(\mathrm{CDCl}_{3}, 100 \mathrm{MHz}\right) \delta=10.81\left(\mathrm{C}-3^{\prime \prime}\right), 28.87\left(\mathrm{C}-2^{\prime \prime}\right), 30.17\left(\left(\mathrm{CH}_{3}\right)_{3}\right), 43.21\left(\mathrm{C}-1^{\prime}\right), 45.94\left(\mathrm{C}-2^{\prime}\right)$, 
$55.17\left(\mathrm{OCH}_{3}\right), 55.70\left(\mathrm{C}-1^{\prime \prime}\right), 61.04\left(\mathrm{CMe}_{3}\right), 92.26(\mathrm{C}-5), 96.89(\mathrm{C}-7), 121.82(\mathrm{C}-3), 129.67(\mathrm{C}-4 \mathrm{a})$, 134.61 (C-4), 135.43 (C-8a), 144.47 (C-2), 145.79 (C-8), 157.40 (C-5 '"'), 159.30 (C-6); HRMS $(\mathrm{EI}+)$ calcd for $\mathrm{C}_{20} \mathrm{H}_{29} \mathrm{~N}_{7} \mathrm{O}: 383.2433$; found: 383.2441 .

$N^{1}$-(6-Methoxyquinolin-8-yl)-N $N^{2}-(($ phenyl)(tert-butyl-1H-tetrazol-5-yl)methyl)ethan-1,2-diamine (8): The reaction of compound $6(163 \mathrm{mg}(0.75 \mathrm{mmol}))$, benzaldehyde $(80 \mathrm{mg}, 76 \mu \mathrm{L}$ $(0.75 \mathrm{mmol}))$, trimethylsilyl azide $(86 \mathrm{mg}, 100 \mu \mathrm{L}(0.75 \mathrm{mmol}))$ and tert-butyl isocyanide $(62 \mathrm{mg}, 85 \mu \mathrm{L}(2.00 \mathrm{mmol}))$ in dry methanol $(5 \mathrm{~mL})$ gave the raw tetrazole which was purified by column chromatography (silica gel, diethyl ether) to yield compound 8 as orange oil $(87 \mathrm{mg}(27 \%))$. IR = 2937, 1578, 1520, 1454, 1423, 1388, 1213, 1154, 1108, 1028, 823, 792; ${ }^{1} \mathrm{H}$ NMR $\left(\mathrm{CDCl}_{3}, 400 \mathrm{MHz}\right) \delta=1.57\left(\mathrm{~s}, 9 \mathrm{H},\left(\mathrm{CH}_{3}\right)_{3}\right), 2.40(\mathrm{br}, 1 \mathrm{H}, \mathrm{NH}), 2.90(\mathrm{dt}$, $\left.J=12.0,6.0 \mathrm{~Hz}, 1 \mathrm{H}, 2^{\prime}-\mathrm{H}\right), 3.02\left(\mathrm{dt}, J=12.0,6.0 \mathrm{~Hz}, 1 \mathrm{H}, 2^{\prime}-\mathrm{H}\right), 3.37-3.42\left(\mathrm{~m}, 2 \mathrm{H}, 1^{\prime}-\mathrm{H}\right), 3.88$ $\left(\mathrm{s}, 3 \mathrm{H}, \mathrm{OCH}_{3}\right), 5.38\left(\mathrm{~s}, 1 \mathrm{H}, 1^{\prime \prime}-\mathrm{H}\right), 6.30(\mathrm{~d}, J=2.5 \mathrm{~Hz}, 1 \mathrm{H}, 7-\mathrm{H}), 6.37(\mathrm{~d}, J=2.5 \mathrm{~Hz}, 1 \mathrm{H}, 5-\mathrm{H})$, 6.50 (br, 1H, NH), 7.27-7.35 (m, 6H, 3-H, aromatic H), $7.93(\mathrm{dd}, J=8.2,1.5 \mathrm{~Hz}, 1 \mathrm{H}, 4-\mathrm{H})$, $8.55(\mathrm{dd}, J=4.1,1.5 \mathrm{~Hz}, 1 \mathrm{H}, 2-\mathrm{H}) ;{ }^{13} \mathrm{C} \mathrm{NMR}\left(\mathrm{CDCl}_{3}, 100 \mathrm{MHz}\right) \delta=29.90\left(\left(\mathrm{CH}_{3}\right)_{3}\right), 43.12$ $\left(\mathrm{C}-1^{\prime}\right), 46.34\left(\mathrm{C}-2^{\prime}\right), 55.20\left(\mathrm{OCH}_{3}\right), 58.78\left(\mathrm{C}-1^{\prime \prime}\right), 61.33\left(\mathrm{CMe}_{3}\right), 92.32(\mathrm{C}-5), 96.95(\mathrm{C}-7), 121.86$ (C-3), 128.11, 128.35, 128.91 (aromatic C), 129.70 (C-4a), 134.64 (C-4), 135.43 (C-8a), 138.64 (aromatic $\mathrm{C}_{\mathrm{q}}$ ), 144.50 (C-2), $145.73(\mathrm{C}-8), 155.51$ (C-5 $\left.{ }^{\prime \prime \prime}\right), 159.32$ (C-6); HRMS (EI+) calcd for $\mathrm{C}_{24} \mathrm{H}_{29} \mathrm{~N}_{7} \mathrm{O}: 431.2433$; found: 431.2435 .

$N^{1}$-((4-Fluorophenyl)(tert-butyl-1H-tetrazol-5-yl)methyl)-N2-(6-methoxyquinolin-8-yl)ethan-1,2diamine (9): The reaction of compound $6(163 \mathrm{mg}(0.75 \mathrm{mmol}))$, 4-fluorobenzaldehyde $(93 \mathrm{mg}, 81 \mu \mathrm{L}(0.75 \mathrm{mmol}))$, trimethylsilyl azide $(86 \mathrm{mg}, 100 \mu \mathrm{L}(0.75 \mathrm{mmol}))$ and tert-butyl isocyanide $(62 \mathrm{mg}, 85 \mu \mathrm{L}(2.00 \mathrm{mmol}))$ in dry methanol $(5 \mathrm{~mL})$ gave the raw tetrazole which was purified by column chromatography (silica gel, diethyl ether) to yield compound 9 as yellow oil (206 mg (61\%)). IR = 2938, 1619, 1578, 1520, 1459, 1423, 1388, 1215, 1156, 1109, 824, 792; ${ }^{1} \mathrm{H}$ NMR $\left(\mathrm{CDCl}_{3}, 400 \mathrm{MHz}\right) \delta=1.57\left(\mathrm{~s}, 9 \mathrm{H},\left(\mathrm{CH}_{3}\right)_{3}\right), 2.44(\mathrm{br}, 1 \mathrm{H}, \mathrm{NH}), 2.89(\mathrm{dt}$, $\left.J=12.2,6.1 \mathrm{~Hz}, 1 \mathrm{H}, 2^{\prime}-\mathrm{H}\right), 2.99\left(\mathrm{dt}, J=12.2,6.1 \mathrm{~Hz}, 1 \mathrm{H}, 2^{\prime}-\mathrm{H}\right), 3.38-3.43\left(\mathrm{~m}, 2 \mathrm{H}, 1^{\prime}-\mathrm{H}\right), 3.88$ $\left(\mathrm{s}, 3 \mathrm{H}, \mathrm{OCH}_{3}\right), 5.36\left(\mathrm{~s}, 1 \mathrm{H}, 1^{\prime \prime}-\mathrm{H}\right), 6.29(\mathrm{~d}, J=2.5 \mathrm{~Hz}, 1 \mathrm{H}, 7-\mathrm{H}), 6.38(\mathrm{~d}, J=2.5 \mathrm{~Hz}, 1 \mathrm{H}, 5-\mathrm{H})$, $6.49(\mathrm{br}, 1 \mathrm{H}, \mathrm{NH}), 6.98-7.03(\mathrm{~m}, 2 \mathrm{H}$, aromatic $\mathrm{H}), 7.27-7.34(\mathrm{~m}, 3 \mathrm{H}, 3-\mathrm{H}$, aromatic $\mathrm{H}), 7.94$ $(\mathrm{dd}, J=8.2,1.6 \mathrm{~Hz}, 1 \mathrm{H}, 4-\mathrm{H}), 8.55(\mathrm{dd}, J=4.2,1.6 \mathrm{~Hz}, 1 \mathrm{H}, 2-\mathrm{H}) ;{ }^{13} \mathrm{C} \mathrm{NMR}\left(\mathrm{CDCl}_{3}, 100 \mathrm{MHz}\right)$ $\delta=29.92\left(\left(\mathrm{CH}_{3}\right)_{3}\right), 43.09\left(\mathrm{C}-1^{\prime}\right), 46.21\left(\mathrm{C}-2^{\prime}\right), 55.20\left(\mathrm{OCH}_{3}\right), 58.03\left(\mathrm{C}-1^{\prime \prime}\right), 61.37\left(\mathrm{CMe}_{3}\right), 92.39$ (C-5), 97.04 (C-7), $115.81(\mathrm{~d}, J=21.8 \mathrm{~Hz}$, aromatic C), 121.90 (C-3), 129.73 (C-4a), 129.89 (d, J $=8.4 \mathrm{~Hz}$, aromatic C), $134.56\left(\mathrm{~d}, J=3.5 \mathrm{~Hz}\right.$, aromatic $\left.\mathrm{C}_{\mathrm{q}}\right), 134.68(\mathrm{C}-4), 135.44(\mathrm{C}-8 \mathrm{a}), 144.53$ (C-2), $145.66(\mathrm{C}-8), 155.45\left(\mathrm{C}-5^{\prime \prime \prime}\right), 159.32$ (C-6), 162.49 (d, J = 248 Hz, aromatic $\mathrm{C}_{\mathrm{q}}$ ); HRMS (EI+) calcd for $\mathrm{C}_{24} \mathrm{H}_{28} \mathrm{FN}_{7} \mathrm{O}$ : 449.2339 ; found: 449.2348 .

$N^{1}$-((4-Chlorophenyl)(tert-butyl-1H-tetrazol-5-yl)methyl)-N2-(6-methoxyquinolin-8-yl)ethan-1,2diamine (10): The reaction of compound 6 (163 $\mathrm{mg}(0.75 \mathrm{mmol}))$, 4-chlorobenzaldehyde (105 mg (0.75 mmol)), trimethylsilyl azide $(86 \mathrm{mg}, 100 \mu \mathrm{L}(0.75 \mathrm{mmol}))$ and tert-butyl isocyanide $(62 \mathrm{mg}, 85 \mu \mathrm{L}(2.00 \mathrm{mmol}))$ in dry methanol $(5 \mathrm{~mL})$ gave the raw tetrazole which was purified by column chromatography (silica gel, diethyl ether) to yield compound $\mathbf{1 0}$ as yellow oil $(73 \mathrm{mg}(21 \%))$. IR = 2938, 1619, 1578, 1520, 1458, 1423, 1388, 1213, 1154, 1091, 1014, 821, 791, 730; ${ }^{1} \mathrm{H} \mathrm{NMR}\left(\mathrm{CDCl}_{3}, 400 \mathrm{MHz}\right) \delta=1.57\left(\mathrm{~s}, 9 \mathrm{H},\left(\mathrm{CH}_{3}\right)_{3}\right), 2.46(\mathrm{br}, 1 \mathrm{H}, \mathrm{NH})$, $2.88\left(\mathrm{dt}, J=12.0,6.0 \mathrm{~Hz}, 1 \mathrm{H}, 2^{\prime}-\mathrm{H}\right), 2.99\left(\mathrm{dt}, J=12.0,6.0 \mathrm{~Hz}, 1 \mathrm{H}, 2^{\prime}-\mathrm{H}\right), 3.37-3.42(\mathrm{~m}, 2 \mathrm{H}$, $\left.1^{\prime}-\mathrm{H}\right), 3.88\left(\mathrm{~s}, 3 \mathrm{H}, \mathrm{OCH}_{3}\right), 5.35\left(\mathrm{~s}, 1 \mathrm{H}, 1^{\prime \prime}-\mathrm{H}\right), 6.29(\mathrm{~d}, J=2.0 \mathrm{~Hz}, 1 \mathrm{H}, 7-\mathrm{H}), 6.37(\mathrm{~d}, J=2.0 \mathrm{~Hz}$, $1 \mathrm{H}, 5-\mathrm{H}), 6.49(\mathrm{br}, 1 \mathrm{H}, \mathrm{NH}), 7.25(\mathrm{~d}, J=8.5 \mathrm{~Hz}, 2 \mathrm{H}$, aromatic H), $7.29(\mathrm{~d}, J=8.5 \mathrm{~Hz}, 2 \mathrm{H}$, aromatic H), $7.31(\mathrm{dd}, J=8.3,4.1 \mathrm{~Hz}, 1 \mathrm{H}, 3-\mathrm{H}), 7.93(\mathrm{dd}, J=8.3,1.6 \mathrm{~Hz}, 1 \mathrm{H}, 4-\mathrm{H}), 8.55(\mathrm{dd}$, $J=4.1 \mathrm{~Hz}, 1 \mathrm{H}, 2-\mathrm{H}) ;{ }^{13} \mathrm{C} \mathrm{NMR}\left(\mathrm{CDCl}_{3}, 100 \mathrm{MHz}\right) \delta=29.95\left(\left(\mathrm{CH}_{3}\right)_{3}\right), 43.06\left(\mathrm{C}-1^{\prime}\right), 46.12$ $\left(\mathrm{C}-2^{\prime}\right), 55.22\left(\mathrm{OCH}_{3}\right), 58.08\left(\mathrm{C}-1^{\prime \prime}\right), 61.41\left(\mathrm{CMe}_{3}\right), 92.41(\mathrm{C}-5), 97.07(\mathrm{C}-7), 121.91(\mathrm{C}-3), 129.06$, 129.51 (aromatic C), 129.73 (C-4a), 134.31 (aromatic $\mathrm{C}_{\mathrm{q}}$ ), 134.69 (C-4), 135.44 (C-8a), 137.22 (aromatic $\mathrm{C}_{\mathrm{q}}$ ), $144.54(\mathrm{C}-2), 145.64(\mathrm{C}-8), 155.23\left(\mathrm{C}-5^{\prime \prime \prime}\right)$, 159.32 (C-6); HRMS (EI+) calcd for $\mathrm{C}_{24} \mathrm{H}_{28} \mathrm{ClN}_{7} \mathrm{O}$ : 465.2044; found: 465.2051 .

$N^{1}$-((4-Bromophenyl)(tert-butyl-1H-tetrazol-5-yl)methyl)-N2-(6-methoxyquinolin-8-yl)ethan-1,2diamine (11): The reaction of compound 6 (163 $\mathrm{mg}(0.75 \mathrm{mmol}))$, 4-bromobenzaldehyde (139 mg (0.75 mmol)), trimethylsilyl azide $(86 \mathrm{mg}, 100 \mu \mathrm{L}(0.75 \mathrm{mmol}))$ and tert-butyl 
isocyanide $(62 \mathrm{mg}, 85 \mu \mathrm{L}(2.00 \mathrm{mmol}))$ in dry methanol $(5 \mathrm{~mL})$ gave the raw tetrazole which was purified by column chromatography (silica gel, diethyl ether) to yield compound 11 as yellow oil $(123 \mathrm{mg}(32 \%))$. IR = 2936, 1619, 1578, 1520, 1458, 1388, 1213, 1154, 1107, 1010, 821, 791; ${ }^{1} \mathrm{H}$ NMR $\left(\mathrm{CDCl}_{3}, 400 \mathrm{MHz}\right) \delta=1.58\left(\mathrm{~s}, 9 \mathrm{H},\left(\mathrm{CH}_{3}\right)_{3}\right), 2.46(\mathrm{br}, 1 \mathrm{H}, \mathrm{NH}), 2.89(\mathrm{dt}$, $\left.J=12.0,6.0 \mathrm{~Hz}, 1 \mathrm{H}, 2^{\prime}-\mathrm{H}\right), 2.99\left(\mathrm{dt}, J=12.0,6.0 \mathrm{~Hz}, 1 \mathrm{H}, 2^{\prime}-\mathrm{H}\right), 3.37-3.42\left(\mathrm{~m}, 2 \mathrm{H}, 1^{\prime}-\mathrm{H}\right)$, $3.89\left(\mathrm{~s}, 3 \mathrm{H}, \mathrm{OCH}_{3}\right), 5.34\left(\mathrm{~s}, 1 \mathrm{H}, 1^{\prime \prime}-\mathrm{H}\right), 6.29(\mathrm{~d}, J=2.5 \mathrm{~Hz}, 1 \mathrm{H}, 7-\mathrm{H}), 6.38$ (d, J = $2.5 \mathrm{~Hz}$, $1 \mathrm{H}, 5-\mathrm{H}), 6.50(\mathrm{br}, 1 \mathrm{H}, \mathrm{NH}), 7.19(\mathrm{~d}, J=8.4 \mathrm{~Hz}, 2 \mathrm{H}$, aromatic $\mathrm{H}), 7.32(\mathrm{dd}, J=8.2,4.2 \mathrm{~Hz}$, $1 \mathrm{H}, 3-\mathrm{H}), 7.44(\mathrm{~d}, J=8.4 \mathrm{~Hz}, 2 \mathrm{H}$, aromatic $\mathrm{H}), 7.94(\mathrm{dd}, J=8.2,1.6 \mathrm{~Hz}, 1 \mathrm{H}, 4-\mathrm{H}), 8.55(\mathrm{dd}$, $J=4.2,1.6 \mathrm{~Hz}, 1 \mathrm{H}, 2-\mathrm{H}) ;{ }^{13} \mathrm{C} \mathrm{NMR}\left(\mathrm{CDCl}_{3}, 100 \mathrm{MHz}\right) \delta=29.99\left(\left(\mathrm{CH}_{3}\right)_{3}\right), 43.09\left(\mathrm{C}-1^{\prime}\right), 46.23$ $\left(\mathrm{C}-2^{\prime}\right), 55.25\left(\mathrm{OCH}_{3}\right), 58.18\left(\mathrm{C}-1^{\prime \prime}\right), 61.44\left(\mathrm{CMe}_{3}\right), 92.44(\mathrm{C}-5), 97.11(\mathrm{C}-7), 121.94(\mathrm{C}-3), 122.52$ (aromatic $\mathrm{C}_{\mathrm{q}}$ ), $129.76(\mathrm{C}-4 \mathrm{a}), 129.85,132.06$ (aromatic C), $134.73(\mathrm{C}-4), 135.45(\mathrm{C}-8 \mathrm{a}), 137.75$ (aromatic $\mathrm{C}_{\mathrm{q}}$ ), $144.56(\mathrm{C}-2), 145.65(\mathrm{C}-8), 155.18$ (C-5 $\left.{ }^{\prime \prime \prime}\right), 159.34(\mathrm{C}-6)$; HRMS (EI+) calcd for $\mathrm{C}_{24} \mathrm{H}_{28} \mathrm{BrN}_{7} \mathrm{O}$ : 509.1539; found: 509.1533 .

$N^{1}-(6-M e t h o x y q u i n o l i n-8-y l)-N^{2}-((t e r t-b u t y l-1 H$-tetrazol-5-yl)(2-(trifluoromethyl)phenyl) methyl)ethan-1,2-diamine (12): The reaction of compound 6 (163 $\mathrm{mg}(0.75 \mathrm{mmol}))$, 4-(trifluoromethyl) benzaldehyde $(131 \mathrm{mg}, 102 \mu \mathrm{L}(0.75 \mathrm{mmol}))$, trimethylsilyl azide $(86 \mathrm{mg}, 100 \mu \mathrm{L}(0.75 \mathrm{mmol}))$ and tert-butyl isocyanide $(62 \mathrm{mg}, 85 \mu \mathrm{L}(2.00 \mathrm{mmol}))$ in dry methanol $(5 \mathrm{~mL})$ gave the raw tetrazole which was purified by column chromatography (silica gel, diethyl ether) to yield compound 12 as yellow oil (56 mg (15\%)). IR = 2937, 1619, 1579, 1521, 1457, 1424, 1389, $1335,1313,1264,1214,1164,1115,1036,823,771 ;{ }^{1} \mathrm{H} \mathrm{NMR}\left(\mathrm{CDCl}_{3}, 400 \mathrm{MHz}\right) \delta=1.73$ (s, 9H, $\left.\left(\mathrm{CH}_{3}\right)_{3}\right), 2.26(\mathrm{br}, 1 \mathrm{H}, \mathrm{NH}), 2.93\left(\mathrm{t}, J=6.0 \mathrm{~Hz}, 2 \mathrm{H}, 2^{\prime}-\mathrm{H}\right), 3.32-3.46\left(\mathrm{~m}, 2 \mathrm{H}, 1^{\prime}-\mathrm{H}\right), 3.87(\mathrm{~s}$, $\left.3 \mathrm{H}, \mathrm{OCH}_{3}\right), 5.84\left(\mathrm{~s}, 1 \mathrm{H}, 1^{\prime \prime}-\mathrm{H}\right), 6.25(\mathrm{~d}, J=2.5 \mathrm{~Hz}, 1 \mathrm{H}, 7-\mathrm{H}), 6.37(\mathrm{~d}, J=2.5 \mathrm{~Hz}, 1 \mathrm{H}, 5-\mathrm{H})$, 6.38-6.41 (m, 1H, NH), $7.31(\mathrm{dd}, J=8.3,4.2 \mathrm{~Hz}, 1 \mathrm{H}, 3-\mathrm{H}), 7.44(\mathrm{t}, J=7.6 \mathrm{~Hz}, 1 \mathrm{H}$, aromatic H), $7.55(\mathrm{t}, J=7.5 \mathrm{~Hz}, 1 \mathrm{H}$, aromatic $\mathrm{H}), 7.61(\mathrm{~d}, J=7.5 \mathrm{~Hz}, 1 \mathrm{H}$, aromatic $\mathrm{H}), 7.71(\mathrm{~d}, J=7.6 \mathrm{~Hz}$, $1 \mathrm{H}$, aromatic $\mathrm{H}), 7.93(\mathrm{dd}, J=8.3,1.6 \mathrm{~Hz}, 1 \mathrm{H}, 4-\mathrm{H}), 8.52(\mathrm{dd}, J=4.2,1.6 \mathrm{~Hz}, 1 \mathrm{H}, 2-\mathrm{H}) ;{ }^{13} \mathrm{C}$ $\mathrm{NMR}\left(\mathrm{CDCl}_{3}, 100 \mathrm{MHz}\right) \delta=29.75\left(\left(\mathrm{CH}_{3}\right)_{3}\right), 42.94\left(\mathrm{C}-1^{\prime}\right), 46.78\left(\mathrm{C}-2^{\prime}\right), 53.81\left(\mathrm{C}-1^{\prime \prime}\right), 55.21$ $\left(\mathrm{OCH}_{3}\right), 62.38\left(\mathrm{CMe}_{3}\right), 92.42(\mathrm{C}-5), 96.91(\mathrm{C}-7), 121.91(\mathrm{C}-3), 124.44\left(\mathrm{q}, \mathrm{J}=274 \mathrm{~Hz}, \mathrm{CF}_{3}\right)$, $126.51\left(\mathrm{q}, J=5.9 \mathrm{~Hz}\right.$, aromatic C), 128.34 (aromatic C), $128.42\left(\mathrm{q}, J=30.1 \mathrm{~Hz}\right.$, aromatic $\mathrm{C}_{\mathrm{q}}$ ), 129.24 (aromatic C), 129.68 (C-4a), 132.45 (aromatic C), 134.65 (C-4), 135.40 (C-8a), 136.75 (aromatic $\mathrm{C}_{\mathrm{q}}$ ), $144.48(\mathrm{C}-2), 145.57$ (C-8), 154.65 (C-5'"'), 159.29 (C-6); HRMS (EI+) calcd for $\mathrm{C}_{25} \mathrm{H}_{28} \mathrm{~F}_{3} \mathrm{~N}_{7} \mathrm{O}: 499.2307$; found: 499.2317 .

6-Methoxy-N-(1-(1-tert-butyl-1H-tetrazol-5-yl)propyl)quinolin-8-amine (13): The reaction of 6-methoxyquinolin-8-amine 2 (131 mg (0.75 mmol)), propanal (44 mg, $54 \mu \mathrm{L}(0.75 \mathrm{mmol})$ ), trimethylsilyl azide $(86 \mathrm{mg}, 100 \mu \mathrm{L}(0.75 \mathrm{mmol}))$ and tert-butyl isocyanide $(62 \mathrm{mg}, 85 \mu \mathrm{L}$ $(2.00 \mathrm{mmol}))$ in dry methanol $(5 \mathrm{~mL})$ gave the raw tetrazole which was purified by column chromatography (silica gel, $\mathrm{CH}_{2} \mathrm{Cl}_{2} / \mathrm{MeOH}$ 80:1) to yield compound $\mathbf{1 3}$ as yellow oil $(107 \mathrm{mg}(42 \%))$. IR = 2966, 2937, 1620, 1596, 1579, 1520, 1454, 1422, 1391, 1339, 1324, 1220, $1195,1169,1125,1064,1050,1031,899,838,820,792 ;{ }^{1} \mathrm{H} \mathrm{NMR}\left(\mathrm{CDCl}_{3}, 400 \mathrm{MHz}\right) \delta=1.01(\mathrm{t}$, $\left.J=7.4 \mathrm{~Hz}, 3 \mathrm{H}, 3^{\prime}-\mathrm{H}\right), 1.76\left(\mathrm{~s}, 9 \mathrm{H},\left(\mathrm{CH}_{3}\right)_{3}\right), 2.21-2.41\left(\mathrm{~m}, 2 \mathrm{H}, 2^{\prime}-\mathrm{H}\right), 3.91\left(\mathrm{~s}, 3 \mathrm{H}, \mathrm{OCH}_{3}\right), 5.08$ $\left(\mathrm{td}, J=9.0,5.5 \mathrm{~Hz}, 1 \mathrm{H}, 1^{\prime}-\mathrm{H}\right), 6.37(\mathrm{~d}, J=1.6 \mathrm{~Hz}, 1 \mathrm{H}, 7-\mathrm{H}), 6.43(\mathrm{~d}, J=1.6 \mathrm{~Hz}, 1 \mathrm{H}, 5-\mathrm{H}), 6.63$ $(\mathrm{d}, J=9.0 \mathrm{~Hz}, 1 \mathrm{H}, \mathrm{NH}), 7.33(\mathrm{dd}, J=8.3,4.2 \mathrm{~Hz}, 1 \mathrm{H}, 3-\mathrm{H}), 7.94(\mathrm{dd}, J=8.3,1.6 \mathrm{~Hz}, 1 \mathrm{H}, 4-\mathrm{H})$, $8.54(\mathrm{dd}, J=4.2,1.6 \mathrm{~Hz}, 1 \mathrm{H}, 2-\mathrm{H}) ;{ }^{13} \mathrm{C} \mathrm{NMR}\left(\mathrm{CDCl}_{3}, 100 \mathrm{MHz}\right) \delta=10.82\left(\mathrm{C}-3^{\prime}\right), 26.98\left(\mathrm{C}-2^{\prime}\right)$, $30.10\left(\left(\mathrm{CH}_{3}\right)_{3}\right), 50.43\left(\mathrm{C}-1^{\prime}\right), 55.31\left(\mathrm{OCH}_{3}\right), 61.53\left(\mathrm{CMe}_{3}\right), 93.11(\mathrm{C}-5), 97.25(\mathrm{C}-7), 122.24$ (C-3), 129.80 (C-4a), 134.69 (C-4), 135.34 (C-8a), 143.57 (C-8), 144.99 (C-2), $155.09\left(\mathrm{C}-5^{\prime \prime}\right)$, 158.86 (C-6); HRMS (EI+) calcd for $\mathrm{C}_{18} \mathrm{H}_{24} \mathrm{~N}_{6} \mathrm{O}$ : 340.2012; found: 340.2024.

6-Methoxy-N-((phenyl)(1-tert-butyl-1H-tetrazol-5-yl)methyl)quinolin-8-amine (14): The reaction of 6-methoxyquinolin-8-amine $2(131 \mathrm{mg}(0.75 \mathrm{mmol}))$, benzaldehyde $(80 \mathrm{mg}, 76 \mu \mathrm{L}$ $(0.75 \mathrm{mmol}))$, trimethylsilyl azide $(86 \mathrm{mg}, 100 \mu \mathrm{L}(0.75 \mathrm{mmol}))$ and tert-butyl isocyanide $(62 \mathrm{mg}, 85 \mu \mathrm{L}(2.00 \mathrm{mmol}))$ in dry methanol $(5 \mathrm{~mL})$ gave the raw tetrazole which was purified by column chromatography (silica gel, $\mathrm{CH}_{2} \mathrm{Cl}_{2} / \mathrm{MeOH} 80: 1$ ) to yield compound 14 as yellow oil $(64 \mathrm{mg}(22 \%))$. IR = 2978, 2938, 1624, 1596, 1580, 1519, 1494, 1453, 1421, $1392,1337,1216,1163,1066,1025,824,789,735 ;{ }^{1} \mathrm{H} \mathrm{NMR}\left(\mathrm{CDCl}_{3}, 400 \mathrm{MHz}\right) \delta=1.75(\mathrm{~s}, 9 \mathrm{H}$, $\left.\left(\mathrm{CH}_{3}\right)_{3}\right), 3.82\left(\mathrm{~s}, 3 \mathrm{H}, \mathrm{OCH}_{3}\right), 6.24(\mathrm{~d}, J=2.3 \mathrm{~Hz}, 1 \mathrm{H}, 7-\mathrm{H}), 6.28\left(\mathrm{~d}, J=8.4 \mathrm{~Hz}, 1 \mathrm{H}, 1^{\prime}-\mathrm{H}\right), 6.40$ 
$(\mathrm{d}, J=2.3 \mathrm{~Hz}, 1 \mathrm{H}, 5-\mathrm{H}), 7.20(\mathrm{~d}, J=8.4 \mathrm{~Hz}, 1 \mathrm{H}, \mathrm{NH}), 7.29(\mathrm{~m}, 4 \mathrm{H}, 3-\mathrm{H}$, aromatic $\mathrm{H}), 7.46$ $(\mathrm{d}, J=7.0 \mathrm{~Hz}, 2 \mathrm{H}$, aromatic $\mathrm{H}), 7.92(\mathrm{dd}, J=8.3,1.6 \mathrm{~Hz}, 1 \mathrm{H}, 4-\mathrm{H}), 8.56(\mathrm{dd}, J=4.2,1.6 \mathrm{~Hz}$, $1 \mathrm{H}, 2-\mathrm{H}) ;{ }^{13} \mathrm{C}$ NMR $\left(\mathrm{CDCl}_{3}, 100 \mathrm{MHz}\right) \delta=30.06\left(\left(\mathrm{CH}_{3}\right)_{3}\right), 53.25\left(\mathrm{C}-1^{\prime}\right), 55.17\left(\mathrm{OCH}_{3}\right), 61.78$ $\left(\mathrm{CMe}_{3}\right), 93.62$ (C-5), 98.33 (C-7), 122.15 (C-3), 127.65, 128.56, 129.00 (aromatic C), 129.62 (C-4a), 134.62 (C-4), 135.26 (C-8a), 137.56 (aromatic $\mathrm{C}_{\mathrm{q}}$ ), 143.17 (C-8), 145.05 (C-2), 154.95 (C-5"), 158.63 (C-6); HRMS (EI+) calcd for $\mathrm{C}_{22} \mathrm{H}_{24} \mathrm{~N}_{6} \mathrm{O}$ : 388.2012; found: 388.2027.

$\mathrm{N}$-((4-Fluorophenyl)(1-tert-butyl-1H-tetrazol-5-yl)methyl)-6-methoxyquinolin-8-amine (15): The reaction of 6-methoxyquinolin-8-amine 2 (131 $\mathrm{mg}(0.75 \mathrm{mmol})$ ), 4-fluorobenzaldehyde $(93 \mathrm{mg}, 81 \mu \mathrm{L}(0.75 \mathrm{mmol}))$, trimethylsilyl azide $(86 \mathrm{mg}, 100 \mu \mathrm{L}(0.75 \mathrm{mmol}))$ and tert-butyl isocyanide $(62 \mathrm{mg}, 85 \mu \mathrm{L}(2.00 \mathrm{mmol}))$ in dry methanol $(5 \mathrm{~mL})$ gave the raw tetrazole which was purified by column chromatography (silica gel, diethyl ether) to yield compound $\mathbf{1 5}$ as orange oil $(95 \mathrm{mg}(31 \%))$. IR $=2985,1622,1579,1512,1454,1422,1389,1337,1218,1160$, 826,$791 ;{ }^{1} \mathrm{H} \mathrm{NMR}\left(\mathrm{CDCl}_{3}, 400 \mathrm{MHz}\right) \delta=1.76\left(\mathrm{~s}, 9 \mathrm{H},\left(\mathrm{CH}_{3}\right)_{3}\right), 3.84\left(\mathrm{~s}, 3 \mathrm{H}, \mathrm{OCH}_{3}\right), 6.22(\mathrm{~d}$, $J=2.5 \mathrm{~Hz}, 1 \mathrm{H}, 7-\mathrm{H}), 6.25\left(\mathrm{~d}, J=8.4 \mathrm{~Hz}, 1 \mathrm{H}, 1^{\prime}-\mathrm{H}\right), 6.43(\mathrm{~d}, J=2.5 \mathrm{~Hz}, 1 \mathrm{H}, 5-\mathrm{H}), 7.02-7.07(\mathrm{~m}$, $2 \mathrm{H}$, aromatic $\mathrm{H}), 7.16(\mathrm{~d}, J=8.4 \mathrm{~Hz}, 1 \mathrm{H}, \mathrm{NH}), 7.34(\mathrm{dd}, J=8.3,4.2 \mathrm{~Hz}, 1 \mathrm{H}, 3-\mathrm{H}), 7.43-7.48$ $(\mathrm{m}, 2 \mathrm{H}$, aromatic $\mathrm{H}), 7.93(\mathrm{dd}, J=8.3,1.5 \mathrm{~Hz}, 1 \mathrm{H}, 4-\mathrm{H}), 8.57(\mathrm{dd}, J=4.2,1.5 \mathrm{~Hz}, 1 \mathrm{H}, 2-\mathrm{H})$; ${ }^{13} \mathrm{C} \mathrm{NMR}\left(\mathrm{CDCl}_{3}, 100 \mathrm{MHz}\right) \delta=30.12\left(\left(\mathrm{CH}_{3}\right)_{3}\right), 52.63\left(\mathrm{C}-1^{\prime}\right), 55.25\left(\mathrm{OCH}_{3}\right), 61.90\left(\mathrm{CMe}_{3}\right)$, $93.84(\mathrm{C}-5), 98.54(\mathrm{C}-7), 116.03(\mathrm{~d}, J=21.8 \mathrm{~Hz}$, aromatic C), $129.41(\mathrm{~d}, J=8.4 \mathrm{~Hz}$, aromatic C), $129.68(\mathrm{C}-4 \mathrm{a}), 133.43(\mathrm{~d}, J=2.8 \mathrm{~Hz}$, aromatic C), 134.70 (C-4), 135.28 (C-8a), 142.98 (C-8), 145.19 (C-2), $154.86\left(\mathrm{C}-5^{\prime \prime}\right), 158.65(\mathrm{C}-6), 162.68\left(\mathrm{~d}, J=248 \mathrm{~Hz}\right.$, aromatic $\mathrm{C}_{\mathrm{q}}$ ); HRMS (EI+) calcd for $\mathrm{C}_{22} \mathrm{H}_{23} \mathrm{FN}_{6} \mathrm{O}: 406.1917$; found: 406.1923 .

$\mathrm{N}$-((4-Chlorophenyl)(1-tert-butyl-1H-tetrazol-5-yl)methyl)-6-methoxyquinolin-8-amine (16): The reaction of 6-methoxyquinolin-8-amine 2 (131 $\mathrm{mg}(0.75 \mathrm{mmol}))$, 4-chlorobenzaldehyde $(105 \mathrm{mg}(0.75 \mathrm{mmol}))$, trimethylsilyl azide $(86 \mathrm{mg}, 100 \mu \mathrm{L}(0.75 \mathrm{mmol}))$ and tert-butyl isocyanide $(62 \mathrm{mg}, 85 \mu \mathrm{L}(2.00 \mathrm{mmol}))$ in dry methanol $(5 \mathrm{~mL})$ gave the raw tetrazole which was purified by column chromatography (silica gel, diethyl ether) followed by precipitation from $\mathrm{MeOH}$ to yield compound 16 as off-white amorphous solid $(19 \mathrm{mg}(6 \%))$. IR = 2992, $1625,1579,1515,1493,1454,1420,1386,1220,1168,1113,1015,822,790 ;{ }^{1} \mathrm{H}$ NMR $\left(\mathrm{CDCl}_{3}\right.$, $400 \mathrm{MHz}) \delta=1.77\left(\mathrm{~s}, 9 \mathrm{H},\left(\mathrm{CH}_{3}\right)_{3}\right), 3.84\left(\mathrm{~s}, 3 \mathrm{H}, \mathrm{OCH}_{3}\right), 6.22(\mathrm{~d}, J=2.5 \mathrm{~Hz}, 1 \mathrm{H}, 7-\mathrm{H}), 6.24$ $\left(\mathrm{d}, J=8.4 \mathrm{~Hz}, 1 \mathrm{H}, \mathrm{1}^{\prime}-\mathrm{H}\right), 6.43(\mathrm{~d}, J=2.5 \mathrm{~Hz}, 1 \mathrm{H}, 5-\mathrm{H}), 7.15(\mathrm{~d}, J=8.4 \mathrm{~Hz}, 1 \mathrm{H}, \mathrm{NH}), 7.32$ $(\mathrm{d}, J=8.5 \mathrm{~Hz}, 2 \mathrm{H}$, aromatic $\mathrm{H}), 7.33(\mathrm{dd}, J=8.3,4.2 \mathrm{~Hz}, 1 \mathrm{H}, 3-\mathrm{H}), 7.42(\mathrm{~d}, J=8.5 \mathrm{~Hz}, 2 \mathrm{H}$, aromatic $\mathrm{H}), 7.93(\mathrm{dd}, J=8.3,1.6 \mathrm{~Hz}, 1 \mathrm{H}, 4-\mathrm{H}), 8.56(\mathrm{dd}, J=4.2,1.6 \mathrm{~Hz}, 1 \mathrm{H}, 2-\mathrm{H}) ;{ }^{13} \mathrm{C}$ NMR $\left(\mathrm{CDCl}_{3}, 100 \mathrm{MHz}\right) \delta=30.12\left(\left(\mathrm{CH}_{3}\right)_{3}\right), 52.68\left(\mathrm{C}-1^{\prime}\right), 55.24\left(\mathrm{OCH}_{3}\right), 61.95\left(\mathrm{CMe}_{3}\right), 93.93(\mathrm{C}-5)$, 98.60 (C-7), 122.29 (C-3), 128.98, 129.23 (aromatic C), 129.68 (C-4a), 134.49 (aromatic $\mathrm{C}_{\mathrm{q}}$ ), 134.70 (C-4), 135.24 (C-8a), 136.19 (aromatic $\mathrm{C}_{\mathrm{q}}$ ), 142.89 (C-8), 145.20 (C-2), 154.63 (C-5"), 158.64 (C-6); HRMS (EI+) calcd for $\mathrm{C}_{22} \mathrm{H}_{23} \mathrm{ClN}_{6} \mathrm{O}: 422.1622$; found: 422.1646 .

$\mathrm{N}$-((4-Bromophenyl)(1-tert-butyl-1H-tetrazol-5-yl)methyl)-6-methoxyquinolin-8-amine (17): The reaction of 6-methoxyquinolin-8-amine 2 (131 $\mathrm{mg}(0.75 \mathrm{mmol}))$, 4-bromobenzaldehyde $(139 \mathrm{mg}(0.75 \mathrm{mmol}))$, trimethylsilyl azide $(86 \mathrm{mg}, 100 \mu \mathrm{L}(0.75 \mathrm{mmol}))$ and tert-butyl isocyanide $(62 \mathrm{mg}, 85 \mu \mathrm{L}(2.00 \mathrm{mmol}))$ in dry methanol $(5 \mathrm{~mL})$ gave the raw tetrazole which precipitated from diethyl ether to yield compound $\mathbf{1 7}$ as off-white amorphous solid (112 mg (32\%)). IR = 2984, 1622, 1579, 1517, 1488, 1454, 1422, 1389, 1216, 1164, 1072, 1011, 824,$791 ;{ }^{1} \mathrm{H}$ NMR $\left(\mathrm{CDCl}_{3}, 400 \mathrm{MHz}\right) \delta=1.77\left(\mathrm{~s}, 9 \mathrm{H},\left(\mathrm{CH}_{3}\right)_{3}\right), 3.84\left(\mathrm{~s}, 3 \mathrm{H}, \mathrm{OCH}_{3}\right), 6.21(\mathrm{~d}$, $J=2.3 \mathrm{~Hz}, 1 \mathrm{H}, 7-\mathrm{H}), 6.22\left(\mathrm{~d}, J=8.4 \mathrm{~Hz}, 1 \mathrm{H}, 1^{\prime}-\mathrm{H}\right), 6.43(\mathrm{~d}, J=2.3 \mathrm{~Hz}, 1 \mathrm{H}, 5-\mathrm{H}), 7.15(\mathrm{~d}$, $J=8.4 \mathrm{~Hz}, 1 \mathrm{H}, \mathrm{NH}), 7.34(\mathrm{dd}, J=8.4,4.4 \mathrm{~Hz}, 1 \mathrm{H}, 3-\mathrm{H}), 7.36(\mathrm{~d}, J=8.4 \mathrm{~Hz}, 2 \mathrm{H}$, aromatic $\mathrm{H}), 7.48(\mathrm{~d}, J=8.4 \mathrm{~Hz}, 2 \mathrm{H}$, aromatic $\mathrm{H}), 7.94(\mathrm{dd}, J=8.4,1.3 \mathrm{~Hz}, 1 \mathrm{H}, 4-\mathrm{H}), 8.56(\mathrm{dd}, J=4.4$, $1.3 \mathrm{~Hz}, 1 \mathrm{H}, 2-\mathrm{H}) ;{ }^{13} \mathrm{C} \mathrm{NMR}\left(\mathrm{CDCl}_{3}, 100 \mathrm{MHz}\right) \delta=30.15\left(\left(\mathrm{CH}_{3}\right)_{3}\right), 52.75\left(\mathrm{C}-1^{\prime}\right), 55.26\left(\mathrm{OCH}_{3}\right)$, $61.97\left(\mathrm{CMe}_{3}\right), 93.94$ (C-5), $98.62(\mathrm{C}-7), 122.31$ (C-3), 122.69 (aromatic $\mathrm{C}_{\mathrm{q}}$ ), 129.30 (aromatic C), 129.70 (C-4a), 132.19 (aromatic C), 134.71 (C-4), 135.25 (C-8a), 136.73 (aromatic $\mathrm{C}_{\mathrm{q}}$ ), 142.88 (C-8), 145.22 (C-2), 154.55 (C-5"), 158.65 (C-6); HRMS (EI+) calcd for $\mathrm{C}_{22} \mathrm{H}_{23} \mathrm{BrN}_{6} \mathrm{O}$ : 466.1117; found: 466.1137.

6-Methoxy-N-((1-tert-butyl-1H-tetrazol-5-yl)(4-(trifluoromethyl)phenyl)methyl)quinolin-8-amine (18): The reaction of 6-methoxyquinolin-8-amine 2 (131 mg (0.75 mmol)), 4-(trifluoromethyl) 
benzaldehyde (131 mg, $102 \mu \mathrm{L}(0.75 \mathrm{mmol}))$, trimethylsilyl azide ( $86 \mathrm{mg}, 100 \mu \mathrm{L}(0.75 \mathrm{mmol}))$ and tert-butyl isocyanide $(62 \mathrm{mg}, 85 \mu \mathrm{L}(2.00 \mathrm{mmol}))$ in dry methanol $(5 \mathrm{~mL})$ gave the raw tetrazole which was purified by column chromatography (silica gel, diethyl ether/petroleum ether 20:1) followed by precipitation from diethyl ether to yield compound $\mathbf{1 8}$ as off-white amorphous solid (17 mg (5\%)). IR = 2936, 1622, 1580, 1515, 1454, 1421, 1388, 1325, 1220, $1168,1112,1068,1018,823,790 ;{ }^{1} \mathrm{H}$ NMR $\left(\mathrm{CDCl}_{3}, 400 \mathrm{MHz}\right) \delta=1.79\left(\mathrm{~s}, 9 \mathrm{H},\left(\mathrm{CH}_{3}\right)_{3}\right), 3.84(\mathrm{~s}$, $\left.3 \mathrm{H}, \mathrm{OCH}_{3}\right), 6.22(\mathrm{~d}, J=2.4 \mathrm{~Hz}, 1 \mathrm{H}, 7-\mathrm{H}), 6.33\left(\mathrm{~d}, J=8.5 \mathrm{~Hz}, 1 \mathrm{H}, 1^{\prime}-\mathrm{H}\right), 6.45(\mathrm{~d}, J=2.4 \mathrm{~Hz}, 1 \mathrm{H}$, 5-H), $7.18(\mathrm{~d}, J=8.5 \mathrm{~Hz}, 1 \mathrm{H}, \mathrm{NH}), 7.36(\mathrm{dd}, J=8.2,4.2 \mathrm{~Hz}, 1 \mathrm{H}, 3-\mathrm{H}), 7.61(\mathrm{~s}, 4 \mathrm{H}$, aromatic $\mathrm{H}), 7.95(\mathrm{dd}, J=8.2,1.4 \mathrm{~Hz}, 1 \mathrm{H}, 4-\mathrm{H}), 8.57(\mathrm{dd}, J=4.2,1.4 \mathrm{~Hz}, 1 \mathrm{H}, 2-\mathrm{H}) ;{ }^{13} \mathrm{C} \mathrm{NMR}\left(\mathrm{CDCl}_{3}\right.$, $100 \mathrm{MHz}) \delta=30.15\left(\left(\mathrm{CH}_{3}\right)_{3}\right), 52.79\left(\mathrm{C}-1^{\prime}\right), 55.27\left(\mathrm{OCH}_{3}\right), 62.08\left(\mathrm{CMe}_{3}\right), 94.09(\mathrm{C}-5), 98.61$ $(\mathrm{C}-7), 122.38(\mathrm{C}-3), 123.84\left(\mathrm{q}, J=272 \mathrm{~Hz}, \mathrm{CF}_{3}\right), 126.02(\mathrm{q}, J=3.8 \mathrm{~Hz}$, aromatic C), 127.94 (aromatic C), $129.72(\mathrm{C}-4 \mathrm{a}), 130.76\left(\mathrm{q}, \mathrm{J}=33.0 \mathrm{~Hz}\right.$, aromatic $\left.\mathrm{C}_{\mathrm{q}}\right), 134.76(\mathrm{C}-4), 135.17(\mathrm{C}-8 \mathrm{a})$, 141.64 (aromatic $\mathrm{C}_{\mathrm{q}}$ ), 142.73 (C-8), 145.29 (C-2), $154.33\left(\mathrm{C}-5^{\prime \prime}\right), 158.63$ (C-6); HRMS (EI+) calcd for $\mathrm{C}_{23} \mathrm{H}_{23} \mathrm{~F}_{3} \mathrm{~N}_{6} \mathrm{O}$ : 456.1885; found: 456.1904 .

6-Methoxy-N-((4-methylphenyl)(1-tert-butyl-1H-tetrazol-5-yl)methyl)quinolin-8-amine (19): The reaction of 6-methoxyquinolin-8-amine $2(131 \mathrm{mg}(0.75 \mathrm{mmol}))$, 4-methylbenzaldehyde $(90 \mathrm{mg}, 88 \mu \mathrm{L}(0.75 \mathrm{mmol}))$, trimethylsilyl azide $(86 \mathrm{mg}, 100 \mu \mathrm{L}(0.75 \mathrm{mmol}))$ and tert-butyl isocyanide $(62 \mathrm{mg}, 85 \mu \mathrm{L}(2.00 \mathrm{mmol}))$ in dry methanol $(5 \mathrm{~mL})$ gave the raw tetrazole which was purified by column chromatography (silica gel, diethyl ether) followed by precipitation from $\mathrm{MeOH}$ to yield compound 19 as off-white amorphous solid (51 $\mathrm{mg}(17 \%)$ ). IR = 2985, $1622,1579,1517,1454,1422,1389,1216,1165,1025,824,791 ;{ }^{1} \mathrm{H} \mathrm{NMR}\left(\mathrm{CDCl}_{3}, 400 \mathrm{MHz}\right)$ $\delta=1.75\left(\mathrm{~s}, 9 \mathrm{H},\left(\mathrm{CH}_{3}\right)_{3}\right), 2.32\left(\mathrm{~s}, 3 \mathrm{H}, \mathrm{CH}_{3}\right), 3.83\left(\mathrm{~s}, 3 \mathrm{H}, \mathrm{OCH}_{3}\right), 6.23(\mathrm{~d}, J=2.3 \mathrm{~Hz}, 1 \mathrm{H}, 7-\mathrm{H})$, $6.24\left(\mathrm{~d}, J=8.4 \mathrm{~Hz}, 1 \mathrm{H}, 1^{\prime}-\mathrm{H}\right), 6.40(\mathrm{~d}, J=2.3 \mathrm{~Hz}, 1 \mathrm{H}, 5-\mathrm{H}), 7.15(\mathrm{~d}, J=7.9 \mathrm{~Hz}, 2 \mathrm{H}$, aromatic $\mathrm{H}), 7.19(\mathrm{~d}, J=8.4 \mathrm{~Hz}, 1 \mathrm{H}, \mathrm{NH}), 7.33(\mathrm{dd}, J=8.1,4.2 \mathrm{~Hz}, 1 \mathrm{H}, 3-\mathrm{H}), 7.34(\mathrm{~d}, J=7.9 \mathrm{~Hz}$, $2 \mathrm{H}$, aromatic $\mathrm{H}), 7.92(\mathrm{dd}, J=8.1,1.6 \mathrm{~Hz}, 1 \mathrm{H}, 4-\mathrm{H}), 8.56(\mathrm{dd}, J=4.2,1.6 \mathrm{~Hz}, 1 \mathrm{H}, 2-\mathrm{H}) ;{ }^{13} \mathrm{C}$ $\mathrm{NMR}\left(\mathrm{CDCl}_{3}, 100 \mathrm{MHz}\right) \delta=21.13\left(\mathrm{CH}_{3}\right), 30.12\left(\left(\mathrm{CH}_{3}\right)_{3}\right), 53.12\left(\mathrm{C}-1^{\prime}\right), 55.21\left(\mathrm{OCH}_{3}\right), 61.77$ $\left(\mathrm{CMe}_{3}\right), 93.58$ (C-5), 98.33 (C-7), 122.16 (C-3), 127.64 (aromatic C), 129.67 (C-4a), 129.74 (aromatic C), $134.61(\mathrm{C}-4), 134.65$ (aromatic $\mathrm{C}_{\mathrm{q}}$ ), $135.40(\mathrm{C}-8 \mathrm{a}), 138.43$ (aromatic $\mathrm{C}_{\mathrm{q}}$ ), 143.34 (C-8), 145.08 (C-2), 155.14 (C-5") 158.73 (C-6); HRMS (EI+) calcd for $\mathrm{C}_{23} \mathrm{H}_{26} \mathrm{~N}_{6} \mathrm{O}$ : 402.2168 ; found: 402.2182 .

6-Methoxy-N-((4-(propan-2-yl)phenyl)(1-tert-butyl-1H-tetrazol-5-yl)methyl)quinolin-8-amine (20): The reaction of 6-methoxyquinolin-8-amine 2 (131 $\mathrm{mg}(0.75 \mathrm{mmol})), 4$-(propan-2-yl) benzaldehyde $(93 \mathrm{mg}, 81 \mu \mathrm{L}(0.75 \mathrm{mmol}))$, trimethylsilyl azide $(86 \mathrm{mg}, 100 \mu \mathrm{L}(0.75 \mathrm{mmol}))$ and tert-butyl isocyanide $(62 \mathrm{mg}, 85 \mu \mathrm{L}(2.00 \mathrm{mmol}))$ in dry methanol $(5 \mathrm{~mL})$ gave the raw tetrazole which was purified by column chromatography (silica gel, diethyl ether) to yield compound 20 as orange oil $(26 \mathrm{mg}(8 \%))$. IR $=2961,1622,1578,1517,1454,1422,1388$, 1216, 1165, 1054, 1024, 906, 824, 730; ${ }^{1} \mathrm{H}$ NMR $\left(\mathrm{CDCl}_{3}, 400 \mathrm{MHz}\right) \delta=1.21(\mathrm{~d}, J=6.9 \mathrm{~Hz}$, $\left.6 \mathrm{H},\left(\mathrm{CH}_{3}\right)_{2}\right), 1.75\left(\mathrm{~s}, 9 \mathrm{H},\left(\mathrm{CH}_{3}\right)_{3}\right), 2.87$ (sept, $\left.J=6.9 \mathrm{~Hz}, 1 \mathrm{H}, \mathrm{CH}\left(\mathrm{CH}_{3}\right)_{2}\right), 3.84\left(\mathrm{~s}, 3 \mathrm{H}, \mathrm{OCH}_{3}\right)$, $6.24(\mathrm{~d}, J=2.3 \mathrm{~Hz}, 1 \mathrm{H}, 7-\mathrm{H}), 6.25\left(\mathrm{~d}, J=8.4 \mathrm{~Hz}, 1 \mathrm{H}, 1^{\prime}-\mathrm{H}\right), 6.40(\mathrm{~d}, J=2.3 \mathrm{~Hz}, 1 \mathrm{H}, 5-\mathrm{H})$, $7.19(\mathrm{~d}, J=8.4 \mathrm{~Hz}, 1 \mathrm{H}, \mathrm{NH}), 7.20(\mathrm{~d}, J=8.1 \mathrm{~Hz}, 2 \mathrm{H}$, aromatic $\mathrm{H}), 7.31(\mathrm{dd}, J=8.3,4.2 \mathrm{~Hz}$, $1 \mathrm{H}, 3-\mathrm{H}), 7.36(\mathrm{~d}, J=8.1 \mathrm{~Hz}, 2 \mathrm{H}$, aromatic $\mathrm{H}), 7.92(\mathrm{dd}, J=8.3,1.5 \mathrm{~Hz}, 1 \mathrm{H}, 4-\mathrm{H}), 8.56(\mathrm{dd}$, $J=4.2,1.5 \mathrm{~Hz}, 1 \mathrm{H}, 2-\mathrm{H}) ;{ }^{13} \mathrm{C} \mathrm{NMR}\left(\mathrm{CDCl}_{3}, 100 \mathrm{MHz}\right) \delta=23.83\left(\left(\mathrm{CH}_{3}\right)_{2}\right), 30.12\left(\left(\mathrm{CH}_{3}\right)_{3}\right)$, $33.75\left(\mathrm{CH}\left(\mathrm{CH}_{3}\right)_{2}\right), 53.07\left(\mathrm{C}-1^{\prime}\right), 55.21\left(\mathrm{OCH}_{3}\right),\left(\mathrm{CMe}_{3}\right), 93.53(\mathrm{C}-5), 98.20(\mathrm{C}-7), 122.15(\mathrm{C}-3)$, 127.11, 127.66 (aromatic C), 129.67 (C-4a), $134.61(\mathrm{C}-4), 134.92$ (aromatic $\left.\mathrm{C}_{\mathrm{q}}\right), 135.37(\mathrm{C}-8 \mathrm{a})$, 143.40 (C-8), 145.06 (C-2), 149.24 (aromatic $\mathrm{C}_{\mathrm{q}}$ ), $155.18\left(\mathrm{C}-5^{\prime \prime}\right), 158.72(\mathrm{C}-6)$; HRMS (EI+) calcd for $\mathrm{C}_{25} \mathrm{H}_{30} \mathrm{~N}_{6} \mathrm{O}: 430.2481$; found: 430.2512 .

6-Methoxy-N-((naphthalen-1-yl)(1-tert-butyl-1H-tetrazol-5-yl)methyl)quinolin-8-amine (21): The reaction of 6-methoxyquinolin-8-amine 2 (131 $\mathrm{mg}(0.75 \mathrm{mmol}))$, naphthalene-1carboxaldehyde $(117 \mathrm{mg}, 102 \mu \mathrm{L}(0.75 \mathrm{mmol}))$, trimethylsilyl azide $(86 \mathrm{mg}, 100 \mu \mathrm{L}(0.75 \mathrm{mmol}))$ and tert-butyl isocyanide $(62 \mathrm{mg}, 85 \mu \mathrm{L}(2.00 \mathrm{mmol}))$ in dry methanol $(5 \mathrm{~mL})$ gave the raw tetrazole which was purified by column chromatography (silica gel, diethyl ether) followed by precipitation from $\mathrm{MeOH}$ to yield compound 21 as off-white amorphous solid $(82 \mathrm{mg}(25 \%))$. IR = 2937, 1619, 1578, 1518, 1452, 1422, 1389, 1278, 1216, 1160, 1047, 1029, 
825, 781, 738; ${ }^{1} \mathrm{H} \mathrm{NMR}\left(\mathrm{CDCl}_{3}, 400 \mathrm{MHz}\right) \delta=1.68\left(\mathrm{~s}, 9 \mathrm{H},\left(\mathrm{CH}_{3}\right)_{3}\right), 3.83\left(\mathrm{~s}, 3 \mathrm{H}, \mathrm{OCH}_{3}\right), 6.23$ $(\mathrm{d}, J=2.4 \mathrm{~Hz}, 1 \mathrm{H}, 7-\mathrm{H}), 6.43(\mathrm{~d}, J=2.4 \mathrm{~Hz}, 1 \mathrm{H}, 5-\mathrm{H}), 6.99\left(\mathrm{~d}, J=9.0 \mathrm{~Hz}, 1 \mathrm{H}, 1^{\prime}-\mathrm{H}\right), 7.09(\mathrm{~d}$, $J=9.0 \mathrm{~Hz}, 1 \mathrm{H}, \mathrm{NH}), 7.18(\mathrm{~d}, J=7.2 \mathrm{~Hz}, 1 \mathrm{H}$, aromatic $\mathrm{H}), 7.29(\mathrm{dd}, J=8.3,4.2 \mathrm{~Hz}, 1 \mathrm{H}, 3-\mathrm{H})$, $7.39(\mathrm{t}, J=7.7 \mathrm{~Hz}, 1 \mathrm{H}$, aromatic $\mathrm{H}), 7.48-7.53(\mathrm{~m}, 2 \mathrm{H}$, aromatic $\mathrm{H}), 7.85-7.98(\mathrm{~m}, 4 \mathrm{H}, 4-\mathrm{H}$, aromatic $\mathrm{H}), 8.50(\mathrm{dd}, J=4.2,1.4 \mathrm{~Hz}, 1 \mathrm{H}, 2-\mathrm{H}) ;{ }^{13} \mathrm{C} \mathrm{NMR}\left(\mathrm{CDCl}_{3}, 100 \mathrm{MHz}\right) \delta=\left(\left(\mathrm{CH}_{3}\right)_{3}\right)$, $50.32\left(\mathrm{C}-1^{\prime}\right), 55.17\left(\mathrm{OCH}_{3}\right), 62.10\left(\mathrm{CMe}_{3}\right), 93.80$ (C-5), $98.15(\mathrm{C}-7), 122.16(\mathrm{C}-3), 122.23,125.35$, 125.91, 126.12, 127.29, 129.16, 129.72 (aromatic C), 129.81 (C-4a), 130.94, 132.97, 134.11 (aromatic $\mathrm{C}_{\mathrm{q}}$ ), 135.44 (C-8a), 143.61 (C-8), 145.08 (C-2), 154.86 (C-5'), 158.70 (C-6); HRMS (EI+) calcd for $\mathrm{C}_{26} \mathrm{H}_{26} \mathrm{~N}_{6} \mathrm{O}: 438.2168$; found: 438.2200 .

6-Methoxy-N-(1-(1-tert-butyl-1H-tetrazol-5-yl)octyl)quinolin-8-amine (22): The reaction of 6methoxyquinolin-8-amine 2 (131 mg (0.75 mmol)), octanal (96 mg, $117 \mu \mathrm{L}(0.75 \mathrm{mmol}))$, trimethylsilyl azide $(86 \mathrm{mg}, 100 \mu \mathrm{L}(0.75 \mathrm{mmol}))$ and tert-butyl isocyanide $(62 \mathrm{mg}, 85 \mu \mathrm{L}$ $(2.00 \mathrm{mmol}))$ in dry methanol $(5 \mathrm{~mL})$ gave the raw tetrazole which was purified by column chromatography (silica gel, diethyl ether/cyclohexane 1:1) to yield compound 22 as light brown oil $(99 \mathrm{mg}(30 \%))$. IR $=2928,2855,1621,1579,1519,1455,1422,1389,1216,1196$, 1166, 1050, 824, 792; ${ }^{1} \mathrm{H}$ NMR $\left(\mathrm{CDCl}_{3}, 400 \mathrm{MHz}\right) \delta=0.85\left(\mathrm{t}, J=7.0 \mathrm{~Hz}, 3 \mathrm{H}, 8^{\prime}-\mathrm{H}\right), 1.17-1.47$ $\left(\mathrm{m}, 10 \mathrm{H}, 3^{\prime}-\mathrm{H}, 4^{\prime}-\mathrm{H}, 5^{\prime}-\mathrm{H}, 6^{\prime}-\mathrm{H}, 7^{\prime}-\mathrm{H}\right), 1.76\left(\mathrm{~s}, 9 \mathrm{H},\left(\mathrm{CH}_{3}\right)_{3}\right), 2.15-2.37\left(\mathrm{~m}, 2 \mathrm{H}, 2^{\prime}-\mathrm{H}\right), 3.91$ (s, $\left.3 \mathrm{H}, \mathrm{OCH}_{3}\right), 5.10-5.17\left(\mathrm{~m}, 1 \mathrm{H}, 1^{\prime}-\mathrm{H}\right), 6.36(\mathrm{~d}, J=1.9 \mathrm{~Hz}, 1 \mathrm{H}, 7-\mathrm{H}), 6.43(\mathrm{~d}, J=1.9 \mathrm{~Hz}, 1 \mathrm{H}$, $5-\mathrm{H}), 6.62(\mathrm{~d}, J=9.7 \mathrm{~Hz}, 1 \mathrm{H}, \mathrm{NH}), 7.31(\mathrm{dd}, J=8.2,4.1 \mathrm{~Hz}, 1 \mathrm{H}, 3-\mathrm{H}), 7.93(\mathrm{dd}, J=8.2,1.5 \mathrm{~Hz}$, $1 \mathrm{H}, 4-\mathrm{H}), 8.53(\mathrm{dd}, J=4.1,1.5 \mathrm{~Hz}, 1 \mathrm{H}, 2-\mathrm{H}) ;{ }^{13} \mathrm{C} \mathrm{NMR}\left(\mathrm{CDCl}_{3}, 100 \mathrm{MHz}\right) \delta=13.97\left(\mathrm{C}-8^{\prime}\right)$, $22.52\left(\mathrm{C}-7^{\prime}\right), 26.32\left(\mathrm{C}-3^{\prime}\right), 29.02\left(\mathrm{C}-5^{\prime}\right), 29.33\left(\mathrm{C}-4^{\prime}\right), 30.08\left(\left(\mathrm{CH}_{3}\right)_{3}\right), 31.66\left(\mathrm{C}-6^{\prime}\right), 34.03\left(\mathrm{C}-2^{\prime}\right)$, $49.16\left({\mathrm{C}-1^{\prime}}^{\prime}\right), 55.26\left(\mathrm{OCH}_{3}\right), 61.48\left(\mathrm{CMe}_{3}\right), 93.14(\mathrm{C}-5), 97.23(\mathrm{C}-7), 122.16(\mathrm{C}-3), 129.79(\mathrm{C}-4 \mathrm{a})$, 134.64 (C-4), 135.33 (C-8a), 143.56 (C-8), 144.92 (C-2), 155.36 (C-5”), 158.87 (C-6); HRMS (EI+) calcd for $\mathrm{C}_{23} \mathrm{H}_{34} \mathrm{~N}_{6} \mathrm{O}: 410.2794$; found: 410.2793 .

\subsection{Biological Tests}

\subsubsection{In Vitro Microplate Assay against P. falciparum}

In vitro activity against erythrocytic stages of $P$. falciparum was determined using a ${ }^{3} \mathrm{H}$-hypoxanthine incorporation assay [22,23], using the drug-sensitive NF54 strain [24]. Chloroquine (Sigma C6628) was used as standard. Compounds were dissolved in DMSO at $10 \mathrm{mg} / \mathrm{mL}$ and added to parasite cultures incubated in RPMI 1640 medium without hypoxanthine, supplemented with HEPES (5.94 g/L), $\mathrm{NaHCO}_{3}(2.1 \mathrm{~g} / \mathrm{L})$, neomycin $(100 \mathrm{U} / \mathrm{mL})$, Albumax $(5 \mathrm{~g} / \mathrm{L})$ and washed human red cells $\mathrm{A}^{+}$at $2.5 \%$ hematocrit $(0.3 \%$ parasitemia) Serial drug dilutions of 113 -fold dilution steps covering a range from 100 to $0.002 \mu \mathrm{g} / \mathrm{mL}$ were prepared. The 96-well plates were incubated in a humidified atmosphere at $37{ }^{\circ} \mathrm{C}$; $4 \% \mathrm{CO}_{2}, 3 \% \mathrm{O}_{2}, 93 \% \mathrm{~N}_{2}$. After $48 \mathrm{~h}, 0.05 \mathrm{~mL}$ of ${ }^{3} \mathrm{H}$-hypoxanthine $(=0.5 \mu \mathrm{Ci})$ was added to each well of the plate. The plates were incubated for a further $24 \mathrm{~h}$ under the same conditions. The plates were then harvested with a Betaplate cell harvester (Wallac, Zurich, Switzerland). The red blood cells were transferred onto a glass fiber filter and washed with distilled water. The dried filters were inserted into a plastic foil with $10 \mathrm{~mL}$ of scintillation fluid and counted in a Betaplate liquid scintillation counter (Wallac, Zurich, Switzerland). $\mathrm{IC}_{50}$ values were calculated from sigmoidal inhibition curves by linear regression [25] using Microsoft Excel. Artemisinin and chloroquine were used as control.

\subsubsection{In Vitro Cytotoxicity with L-6 Cells}

Assays were performed in 96-well microtiter plates, each well containing $0.1 \mathrm{~mL}$ of RPMI 1640 medium supplemented with 1\% L-glutamine (200 mM) and 10\% fetal bovine serum and 4000 L-6 cells (a primary cell line derived from rat skeletal myoblasts) [26,27]. Serial drug dilutions of 113 -fold dilution steps covering a range from 100 to $0.002 \mu \mathrm{g} / \mathrm{mL}$ were prepared. After $70 \mathrm{~h}$ of incubation, the plates were inspected under an inverted microscope to assure the growth of the controls and sterile conditions. Then, $0.01 \mathrm{~mL}$ of Alamar Blue was added to each well and the plates incubated for another $2 \mathrm{~h}$. The plates were read with a Spectramax Gemini XS microplate fluorometer (Molecular Devices Cooperation, Sunnyvale, CA, USA) using an excitation wavelength of $536 \mathrm{~nm}$ and an 
emission wavelength of $588 \mathrm{~nm}$. The $\mathrm{IC}_{50}$ values were calculated by linear regression [28] from the sigmoidal dose inhibition curves using SoftmaxPro software (Molecular Devices Cooperation, Sunnyvale, CA, USA). Podophyllotoxin (Sigma P4405) was used as control.

\section{Conclusions}

A series of 8-amino-6-methoxyquinoline hybrids was prepared via Ugi-azide reaction. The compounds exhibit different linkers between a 6-methoxyquinolin-8-amine moiety and a tetrazole ring. Compounds with a short and non-basic linker with lipophilic substitution showed the highest antiplasmodial activity. Six of the new derivates have promising selectivity due to their low cytotoxity. The optimum linker length will be investigated in a future project.

Supplementary Materials: The following are available online. Figures S1-S20: ${ }^{1} \mathrm{H}-$ and ${ }^{13} \mathrm{C}-\mathrm{NMR}$ spectra for compounds 3-22 and IR and MS spectra for compounds 7-22.

Author Contributions: Conceptualization, P.H., J.D. and R.W.; investigation, P.H., J.D., W.S., R.S., M.K., P.M. and R.W.; methodology P.H and J.D.; data curation, P.H., J.D., W.S., R.S., M.K., P.M. and R.W.; writing —original draft preparation, P.H., J.D. and R.W.; writing—review and editing, P.H. and R.W.; supervision, R.W.; project administration, J.D. and R.W. All authors have read and agreed to the published version of the manuscript.

Funding: This research received no external funding.

Institutional Review Board Statement: Not applicable.

Informed Consent Statement: Not applicable.

Data Availability Statement: The data presented in this study are available in this article.

Acknowledgments: The authors acknowledge Open Access Funding by the University of Graz.

Conflicts of Interest: The authors declare no conflict of interest.

Sample Availability: Samples of the compounds are available from the authors.

\section{References}

1. WHO. World Malaria Report; World Health Organization: Geneva, Switzerland, 2020.

2. Talapko, J.; Škrlec, I.; Alebić, T.; Jukić, M.; Včev, A. Malaria: The Past and the Present. Microorganisms 2019, 7, 179. [CrossRef]

3. Ashley, E.A.; Dhorda, M.; Fairhurst, R.M.; Amaratunga, C.; Lim, P.; Suon, S.; Sreng, S.; Anderson, J.M.; Mao, S.; Sam, B.; et al. Spread of Artemisinin Resistance in Plasmodium falciparum Malaria. N. Engl. J. Med. 2014, 371, 411-423. [CrossRef]

4. Das, S.; Manna, S.; Saha, B.; Hati, A.K.; Roy, S. Novel pfkelch13 Gene Polymorphism Associates With Artemisinin Resistance in Eastern India. Clin. Infect. Dis. 2019, 69, 1144-1152. [CrossRef] [PubMed]

5. Hawley, S.R.; Bray, P.G.; Mungthin, M.; Atkinson, J.D.; O’Neill, P.M.; Ward, S.A. Relationship between Antimalarial Drug Activity, Accumulation, and Inhibition of Heme Polymerization in Plasmodium falciparum In Vitro. Antimicrob. Agents Chemother. 1998, 42, 682-686. [CrossRef] [PubMed]

6. Wongsrichanalai, C.; Pickard, A.L.; Wernsdorfer, W.H.; Meshnick, S.R. Epidemiology of drug-resistant malaria. Lancet Infect. Dis. 2002, 2, 209-218. [CrossRef]

7. Hanboonkunupakarn, B.; White, N.J. The threat of antimalarial drug resistance. Trop. Dis. Travel Med. Vaccines 2016, 2, 10. [CrossRef]

8. Kumar, A.; Srivastava, K.; Kumar, S.R.; Siddiqi, M.I.; Puri, S.K.; Sexana, J.K.; Chauhan, P.M.S. 4-Anilinoquinoline triazines: A novel class of hybrid antimalarial agents. Eur. J. Med. Chem. 2011, 46, 676-690. [CrossRef] [PubMed]

9. Manohar, S.; Tripathi, M.; Rawat, D.S. 4-Aminoquinoline Based Molecular Hybrids as Antimalarials: An Overview. Curr. Top. Med. Chem. 2014, 14, 1706-1733. [CrossRef] [PubMed]

10. Pandey, S.; Agarwal, P.; Srivastava, K.; Rajakumar, S.; Puri, S.K.; Verma, P.; Saxena, J.; Sharma, A.; Lal, J.; Chauhan, P.M. Synthesis and bioevaluation of novel 4-aminoquinoline-tetrazole derivatives as potent antimalarial agents. Eur. J. Med. Chem. 2013, 66, 69-81. [CrossRef]

11. Hochegger, P.; Faist, J.; Seebacher, W.; Saf, R.; Mäser, P.; Kaiser, M.; Weis, R. Antiprotozoal Activities of Tetrazole-quinolines with Aminopiperidine Linker. Med. Chem. 2018, 14, 1-8. [CrossRef] [PubMed]

12. Douglas, C.J.; Dreis, A.M. Catalytic Carbon-Carbon $\sigma$ Bond Activation: An Intramolecular Carbo-Acylation Reaction with Acylquinolines. J. Am. Chem. Soc. 2009, 131, 412-413. 
13. Widdowson, K.L.; Elliott, J.D.; Veber, D.F.; Nie, H.; Rutledge, M.C.; McCleland, B.C.; Xiang, J.; Jurewicz, A.J.; Hertzberg, R.P.; Foley, J.J.; et al. Evaluation of Potent and Selective Small-Molecule Antagonists for the CXCR2 Chemokine Receptor. J. Med. Chem. 2009, 47, 1319-1321. [CrossRef] [PubMed]

14. Cárdenas-Galindo, L.E.; Islas-Jácome, A.; Cortes-García, C.J.; El Kaim, L.; Gámez-Montaño, R. Efficient Synthesis of 1,5disubstituted-1H-tetrazoles by an Ugiazide Process. J. Mex. Chem. Soc. 2013, 57, 283-289.

15. Zhou, X.; Yan, W.; Zhao, T.; Tian, Z.; Wu, X. Rhodamine based derivative and its zinc complex: Synthesis and recognition be-havior toward $\mathrm{Hg}(\mathrm{II})$. Tetrahedron 2013, 69, 9535-9539. [CrossRef]

16. Zhu, J.; Yuan, H.; Chan, W.; Lee, A.W.M. A colorimetric and fluorescent turn-on chemosensor operative in aqueous media for $\mathrm{Zn}^{2+}$ based on a multifunctionalized spirobenzopyran derivative. Org. Biomol. Chem. 2010, 8, 3957-3964. [CrossRef]

17. Faist, J.; Seebacher, W.; Kaiser, M.; Brun, R.; Saf, R.; Weis, R. Antiprotozoal activity of bicyclic diamines with a N-methylpiperazinyl group at the bridgehead atom. Bioorg. Med. Chem. 2013, 21, 4988-4996. [CrossRef]

18. Bruce, W.F. Disubstituted Glycyl Derivatives of Amino Quinolines. U.S. Patent US2494083A, 10 January 1950.

19. Bhat, B.; Bhaduri, A.P. Possible Antimalarial Agents: Syntheses of 6-methoxy-8-substituted-aminoquinolines. Indian J. Chem. Sect. B 1985, 24B, 419-423.

20. Baldwin, A.W. Attempts to find new anti-malarials. Part III. Some substituted aminoalkylaminoquinolines. J. Chem. Soc. 1929, 2959-2965. [CrossRef]

21. Beer, A.A. Antimalarial compounds in the series 6-methoxy-8-(aminoalkyl)aminoquinoline. Zhurnal Obs. Khimii 1939, 9, 21582161.

22. Desjardins, R.; Canfield, C.J.; Haynes, J.D.; Chulay, J.D. Quantitative assessment of antimalarial activity in vitro by a semiautomated microdilution technique. Antimicrob. Agents Chemother. 1979, 16, 710-718. [CrossRef]

23. Matile, H.; Richard, J.; Pink, L. Plasmodium falciparum malaria parasite cultures and their use in immunology. In Immuno-logical Methods; Academic Press: San Diego, CA, USA, 1990; Volume 4, pp. 221-234. [CrossRef]

24. Ponnudurai, T.; Leeuwenberg, A.D.; Meuwissen, J.H. Chloroquine sensitivity of isolates of Plasmodium falciparum adapted to in vitro culture. Trop. Geogr. Med. 1981, 33, 50-54.

25. Huber, W.; Koella, J.C. A comparison of three methods of estimating EC50 in studies of drug resistance of malaria parasites. Acta Trop. 1993, 55, 257-261. [CrossRef]

26. Page, B.; Page, M.; Noel, C. A new fluorometric assay for cytotoxicity measurements in-vitro. Int. J. Oncol. 1993, 3, 473-476. [CrossRef] [PubMed]

27. Ahmed, S.A.; Gogal, R.M., Jr.; Walsh, J.E. A new rapid and simple non-radioactive assay to monitor and determine the proliferation of lymphocytes: An alternative to [3H]thymidine incorporation assay. J. Immunol. Methods 1994, 170, 211-224. [CrossRef]

28. Wrobel, J.E.; Rogers, J.F.; Green, D.M.; Kao, W.; Jetter, J.W. Aryl Sulfonic Acids and Derivatives as FSH Antagonists. U.S. Patent US6355633B1, 12 March 2002. 